Historical perspective

\title{
Micro- and nano bio-based delivery systems for food applications: In vitro behavior
}

\author{
Lívia de Souza Simões a , Daniel A. Madalena ${ }^{a}$, Ana C. Pinheiro ${ }^{\text {a,b }}$, José A. Teixeira ${ }^{\text {a }}$, \\ António A. Vicente ${ }^{\mathrm{a}}$, Óscar L. Ramos ${ }^{\mathrm{a}, \mathrm{c}, *}$ \\ a CEB - Centre of Biological Engineering, University of Minho, Braga, Portugal \\ b Instituto de Biologia Experimental e Tecnológica, Avenida da República, Quinta-do-Marquês, Estação Agronómica Nacional, Apartado 12, 2781-901 Oeiras, Portugal \\ c $L E P A B E$ - Laboratório de Engenharia de Processos, Ambiente, Biotecnologia e Energia, University of Porto, Porto, Portugal
}

\section{A R T I C L E I N F O}

Available online 27 March 2017

\section{Keywords:}

Encapsulation

Micro/Nanosystems

Biomaterials

Bioactive compounds

Bioavailability

Food products

\begin{abstract}
A B S T R A C T
Micro- and nanoencapsulation is an emerging technology in the food field that potentially allows the improvement of food quality and human health. Bio-based delivery systems of bioactive compounds have a wide variety of morphologies that influence their stability and functional performance. The incorporation of bioactive compounds in food products using micro- and nano-delivery systems may offer extra health benefits, beyond basic nutrition, once their encapsulation may provide protection against undesired environmental conditions (e.g., heat, light and oxygen) along the food chain (including processing and storage), thus improving their bioavailability, while enabling their controlled release and target delivery. This review provides an overview of the bio-based materials currently used for encapsulation of bioactive compounds intended for food applications, as well as the main production techniques employed in the development of micro- and nanosystems. The behavior of such systems and of bioactive compounds entrapped into, throughout in vitro gastrointestinal systems, is also tracked in a critical manner. Comparisons between various in vitro digestion systems (including the main advantages and disadvantages) currently in use, as well as correlations between the behavior of micro- and nanosystems studied through in vitro and in vivo systems were highlighted and discussed here for the first time. Finally, examples of bioactive micro- and nanosystems added to food simulants or to real food matrices are provided, together with a revision of the main challenges for their safe commercialization, the regulatory issues involved and the main legislation aspects.
\end{abstract}

(C) 2017 Elsevier B.V. All rights reserved.

\section{Contents}

1. Introduction .

2. Bio-based materials as ingredients for the encapsulating matrix $\ldots \ldots \ldots \ldots$

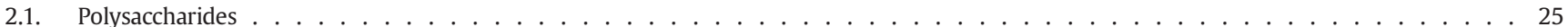

2.2. Proteins . . . . . . . . . . . . . . . . . . . . . . . . . . . . . . . . . . .

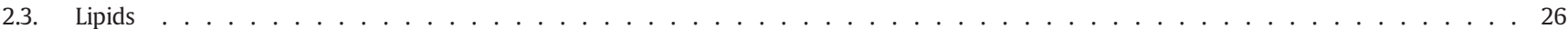

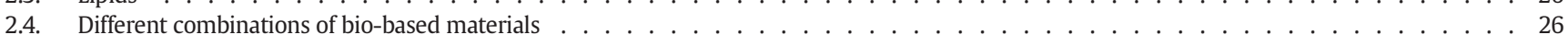

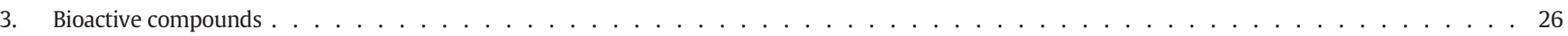

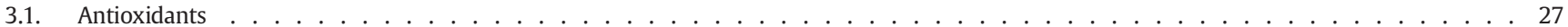

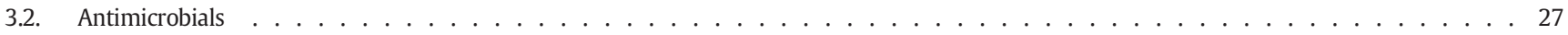

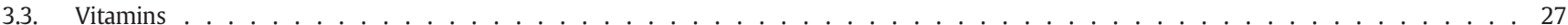

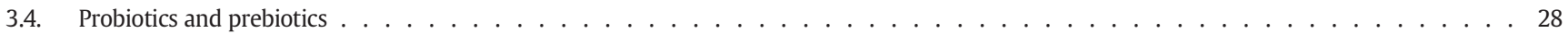

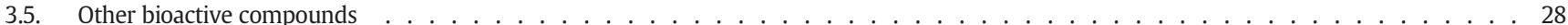

4. Encapsulation techniques . . . . . . . . . . . . . . . . . . . . . . . . . . . . . . 29

4.1. Spray drying . . . . . . . . . . . . . . . . . . . . . . . . . . . . . . . . . . . . . . . . 29

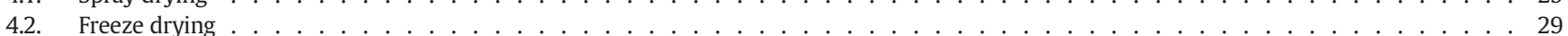

\footnotetext{
* Corresponding author at: CEB - Centre of Biological Engineering, University of Minho, Braga, Portugal.

E-mail address: os.silva.ramos@gmail.com (ó.L. Ramos).
} 


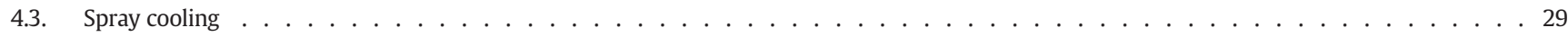

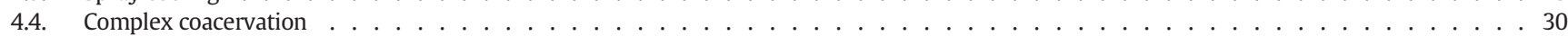

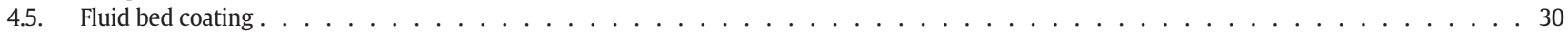

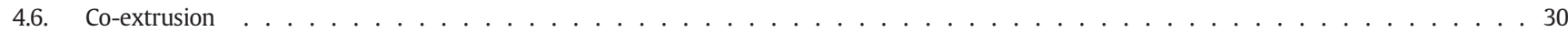

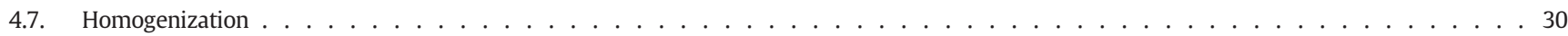

5. Micro- and nanosystems for entrapment of bioactive compounds . . . . . . . . . . . . . . . . . . . . . . . . . . . . 31

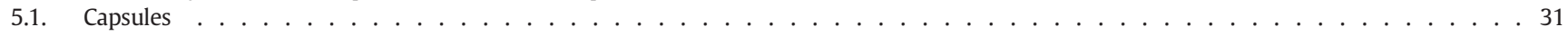

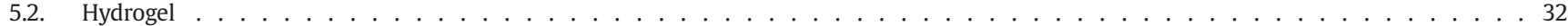

5.3. Lipid-based systems . . . . . . . . . . . . . . . . . . . . . . . . . . . . . . . . . 32

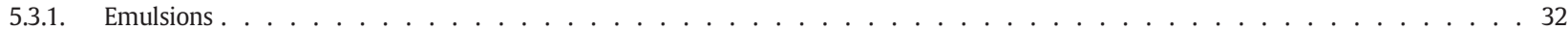

5.3.2. Solid lipid nanoparticles . . . . . . . . . . . . . . . . . . . . . . . . . . . . . . 32

5.3.3. Nanostructured lipid carriers . . . . . . . . . . . . . . . . . . . . . . . . . . . . . . . . . . . 32

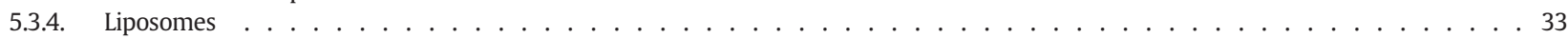

5.4. Comparison between distinct micro- and nanosystems . . . . . . . . . . . . . . . . . . . . . . 33

6. Behavior of micro- and nanosystems and bioavailability of bioactive compounds . . . . . . . . . . . . . . . . . . . . . . . . . 33

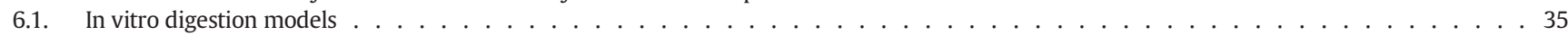

6.2. In vitro static digestion models . . . . . . . . . . . . . . . . . . . . . . . . . . . . . . . . . . 35

6.3. In vitro dynamic digestion models . . . . . . . . . . . . . . . . . . . . . . . . 35

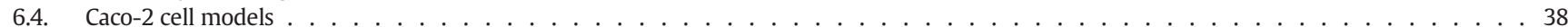

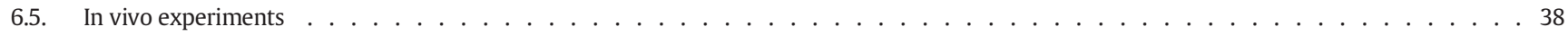

6.6. In vitro-in vivo correlations . . . . . . . . . . . . . . . . . . . . . . . . . . . . . . . . 38

7. Behavior of micro- and nanosystems in food models . . . . . . . . . . . . . . . . . . . . . . . . . . . 38

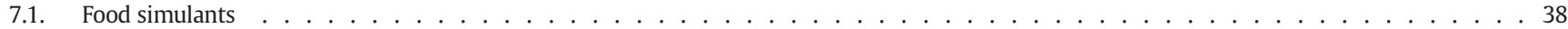

7.2. Food matrices . . . . . . . . . . . . . . . . . . . . . . . . . . . . . . . . .

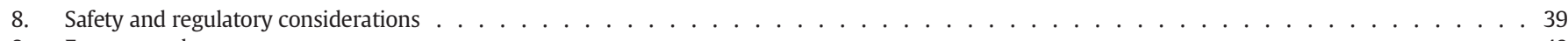

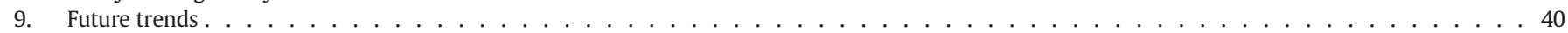

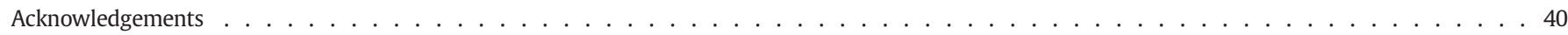

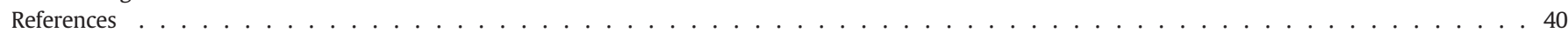

\section{Introduction}

The world's population is increasing every year and, consequently, challenges regarding the production, preservation, safety and sustainability of food products have emerged. Therefore, offering the consumer high quality foods with the required level of bioavailable nutrients and dietetic supplements is a current challenge. The application of microand nanotechnology in food industry may represent a solution for the potential bioavailability issues, providing new solutions and opportunities to address these challenges [1,2].

Materials at micro $\left(10^{-6} \mathrm{~m}\right)$ and nano $\left(10^{-9} \mathrm{~m}\right)$ scale exhibit different physical, chemical and biological properties, which may enhance the properties of such materials or even exhibit novel material functionalities and applications, when compared with those at the macro scale [3]. Due to their reduced size, micro- and nanosystems can improve solubility, bioavailability and sensorial characteristics (e.g., mask unpleasant flavors), prevent undesirable physical and chemical reactions, as well as protect bioactive compounds from degradation. This behavior can be related to the large surface area-to-volume ratio, but also to the effect of physical and chemical interactions between materials, found at lower sized structures (i.e., at micro- and nanoscale), which have a significant effect on the overall properties of those systems [4]. Among these, the incorporation of bioactive compounds in food and the assurance of their stability during processing, storage and digestion, until they reach the appropriate delivery point and timing, are the main concerns regarding the controlled release of bioactive compounds [2]. On the other hand, size reduction promotes a great improvement in bioadhesive properties that may include a significant increase in adhesive forces, prolonging gastrointestinal (GI) transit time, thus leading to a higher bioavailability, when compared with larger particles [5].

One of the major challenges regarding the use of micro- and nanosystems for food applications is the replacement of non-foodgrade materials by bio-based, biodegradable and generally recognized as safe (GRAS) alternatives [6]. Other challenges include the design and application of efficient delivery systems for controlled release of bioactive compounds.
Bioactive compounds are usually labile molecules, highly affected by light, oxygen and temperature when dispersed in the food matrix; therefore their encapsulation may allow the improvement of their bioavailability [7]. Effective delivery systems must be able to maintain the activity and stability of bioactive compounds until their release, in a controlled way, and only activate them in the target site (i.e., some compounds lose their activity when they are mixed with food components, due to their early release). They should also protect bioactive compounds from adverse environmental conditions inherent to food processing and storage (e.g., variation of $\mathrm{pH}$, temperature, ionic strength and enzymatic activity), thus improving their bioavailability. Moreover delivery systems should not affect the physicochemical and sensory properties of the final food products [7]. In the case of delivery systems at nanoscale, their application in food products can be also hindered by the public concerns regarding possible side effects, once particles with their dimensions may penetrate biological tissues, thus leading to disruption of normal function of cells or even cell death, with considerable adverse effects to human health [8].

Hence, the behavior of such compounds should be assessed, primarily, through in vitro assays (i.e., GI system or cell lines, as in vitro models) to evaluate possible nanotoxicity to human body [9]. Current knowledge on possible toxicity caused by particles at nanoscale is very scarce, therefore studies regarding this subject are mandatory.

In the food industry several techniques were developed in order to produce micro- and nanosystems for functional and fortified food products using "top-down" or "bottom-up" approaches or the combination of both strategies [10]. These techniques enable the production of micro- and nanosystems with distinct characteristics (e.g., controlled release and delivery properties) [11].

This review aims at providing a relevant insight concerning the development of micro- and nanosystems using bio-based materials as encapsulating matrix and the main production techniques employed in their formation. The bioactive compounds' entrapment and their controlled release from such micro- and nanosystems will be also addressed in a critical manner. Moreover, the behavior of delivery systems when subjected to in vitro GI tract conditions, possible interactions 
established and correlations with in vivo experiments were shown, together with practical examples of their application in food simulants or in real food matrices. Finally, regulatory considerations, legislation aspects and future trends are also addressed.

\section{Bio-based materials as ingredients for the encapsulating matrix}

Encapsulation is a technique in which small substances (i.e., bioactive compounds) are trapped by a surrounding material to form capsules, at macro- (macroencapsulation) or nano- (nanoencapsulation) scale. This structure can sometimes be an effective protection barrier against environmental agents such as oxygen, light and free radicals. Moreover, micro- and nanoencapsulation has the ability to increase the bioavailability, enhance controlled release and targeting precision of bioactive compounds [12-14]. The release rate of bioactive compounds from micro- and nanosystems is linearly dependent with the surface area of such systems, which is inversely proportional to particle size. Therefore, a decrease in particle size results in an increase of the surface area, and consequently in the release rate of bioactive compounds [15].

The encapsulating materials used as delivery systems can be chosen from natural biomaterials as long as they are safe and classified as Generally Recognized As Safe (GRAS) [16].

Bio-based micro- and nanosystems for food industry can be produced from a wide variety of food-grade materials, including polysaccharides, proteins and lipids, isolated or associated to form complex delivery systems. However, the selection of the appropriate bio-based material requires an understanding of the bioactive compound properties, as well as of the nature of the food matrix, in which such compounds will be incorporated [7,17].

\subsection{Polysaccharides}

Polysaccharides are polymeric carbohydrate molecules composed by several monosaccharide units, bound together by glycosidic linkages. The chemical differences in the polymeric chain regarding the type, number, sequence and linkage of monosaccharides influences the molecular properties of these structures, such as water retention capacity, solubility, digestibility, as well as gelation and emulsification capability $[18,19]$.

Polysaccharides are widely found in Nature and can be obtained from natural sources or from by-products of food industry, mostly through low-cost processing techniques. These polymers present important properties such as good stability, non-toxicity, biodegradability and bioadhesibility that allow their use as delivery systems [20]. Bioadhesibility is of particular relevance, once it contributes to an increase in the residence time of delivery systems in the GI tract [21]. This is mainly due to the intrinsic hydrophilic groups (e.g., hydroxyl, carbonyl and amine) of polysaccharides that enable the formation of non-covalent bonds with biological tissue, thus contributing to higher absorption rates of bioactive compounds entrapped into delivery systems $[22,23]$.

Usually polysaccharide-based delivery systems are organized according to their biological origin: plant (e.g., pectin, guar gum, starch and cellulose), animal (e.g., chitosan), algae (e.g., alginate and carrageenan) and microbial (e.g., dextran and xanthan gum) $[18,19]$. Detailed information regarding the molecular and biological properties, functional performance, and advantages and disadvantages of the main polysaccharides-based delivery systems can be found elsewhere [24].

The most widely used bio-based polysaccharides in the manufacture of micro- and nano-delivery systems include chitosan, alginate, carrageenan and gums (i.e., xanthan gum). Chitosan is a hydrophilic linear polysaccharide that can enhance the cell membrane permeability, thus increasing the bioavailability of bioactive compounds because it extends the residence time of the delivery system in the GI tract [23]. Alginate, obtained from brown seaweeds, is another polysaccharide commonly used as a delivery system base-material [2]. On the other hand, carrageenan is obtained from several species of marine algae, whereas Xanthan gum is produced by microorganism (Xanthomonas campestris) through extracellular aerobic fermentation [25].

Polysaccharide-based delivery systems have the ability to interact with bioactive compounds (i.e., through interactions between functional groups), which makes them versatile carriers to bind and entrap a variety of hydrophilic and hydrophobic functional compounds. Due to their thermal stability, they are suitable protective carriers for labile compounds during food processes that require high temperatures, acting as a suitable alternative to lipid and protein-based delivery systems that melt and denature, respectively [24].

The selection of an appropriate polysaccharide based material to produce micro- and nano-delivery systems is highly dependent of surrounding environmental conditions, once they may associate to other compounds and form different structures. Therefore, the knowledge about their physical and electrical properties, and susceptibility to chemical and enzymatic reactions is of utmost importance [26].

Polysaccharides can also produce micro- and nanosystems by assembling mechanisms through electrostatic interactions based on their intrinsic charge that, depending on the base materials, can be classified as neutral (i.e., amylose, amylopectin, cellulose and guar gum), anionic (i.e., alginates, carrageenans, gellan, and arabic and xanthan gums) and cationic (i.e., chitosan) [27]. The relation between $\mathrm{pH}$ and pKa of the charge groups is of extreme importance to establish the electrical charge level on ionic polysaccharides; for instance, anionic polysaccharides tend to be neutral at pH values considerably below its pKa value, but they acquire a negative charge at $\mathrm{pH}$ values above its $\mathrm{pKa}$ value. On the other hand, cationic polysaccharides tend to be neutral at $\mathrm{pH}$ values above its pKa value, while they acquire a positive charge at $\mathrm{pH}$ values below its pKa value [26].

Depending on the technique employed in the encapsulation of bioactive compounds, delivery systems can be produced using a single or a combination of polysaccharides. Li and McClements [28] showed the successful formation of hydrogel beads with diameter between $25.3 \pm$ $0.1 \mu \mathrm{m}$ and $31.7 \pm 0.4 \mu \mathrm{m}$, using a mixture of two polysaccharides (i.e., alginate and chitosan) through complex coacervation. On the other hand, Birch and Schiffman [29] produced stable nanoparticles during 14 days of storage (in aqueous solution) formed by a mixture of two polysaccharides (i.e., chitosan and pectin).

\subsection{Proteins}

Proteins are biological polymers formed by a sequence of amino acids linked by peptide bonds. There are 20 different amino acids categorized according to the properties of their side groups as aliphatic, aromatic, charged (positive or negative), or polar. The proteins that are frequently used in the food industry are obtained from plant (e.g., soy and zein) and animal (e.g., casein, egg and whey protein) sources, or hydrolysates of these proteins $[16,18,30]$.

The characterization of protein molecules is of utmost importance since the knowledge of their characteristics (i.e., denaturation temperature, isoelectric point and chemical degradation reactions) is crucial for optimizing the necessary production conditions for the development of protein-based delivery systems [26]. Protein molecules interact with each other or with other molecules in their vicinity through electrostatic, covalent, van der Waals, steric, hydrogen, hydrophobic and disulfide bonds [31]. Protein secondary structure (i.e., $\alpha$-helices and $\beta$-sheets) can be organized in adjacent amino acids on protein chains, which may play an important role in the formation, stability and functionality of the resulting structures. The exposure of protein side groups to the environmental conditions is determined by the conformation of the amino acid chain, which affects protein stability and reactivity [32].

Regarding protein electrical characteristics, they can be described according to their $\zeta$-potential profile, which varies with $\mathrm{pH}$. Their electrical 
charge changes from positive (below their isoelectric point - pI), neutral (at their $\mathrm{pl}$ ) and negative (above their $\mathrm{pI}$ ) according with the $\mathrm{pH}$ value. However, when the protein structure is at its pI, the protein has both positive and negative charged groups on its surface, which enable the formation of attractive and/or repulsive electrostatic interactions [2]. Proteins have a high nutritional value and considerable functional properties such as emulsification, gelation, foaming and water binding capacity. Due to their structural versatility, many structures can be produced (i.e., films, particles, fibers, tubules and hydrogels), offering the possibility of delivering both hydrophobic and hydrophilic bioactive compounds [33,34]. Several publication have comprehensively reviewed these subjects $[31,33,35,36]$. Among these functional properties, gelation is particularly important for the manufacture of delivery systems. Gelation typically encompasses two stages: partial unfolding (denaturation) of the native globular structure followed by intermolecular aggregation. Denaturation of the native structure of proteins can be induced by several factors, e.g., addition of chemicals or electrolytes, change in net charge, increase in hydrostatic pressure, partial enzymatic hydrolysis and electrical fields - but mainly by temperature. Each of these processes may induce partial (or total) denaturation of native proteins, which may results in protein aggregation and gel formation [20].

When globular proteins are heated until reaching their denaturation temperature, they start to unfold (i.e., the nonpolar groups, normally buried within the protein structure, are exposed), and may interact with other protein structures, forming different types of aggregates (e.g., fibrillar or particulate aggregates) with diverse mechanical and microstructural properties. Moreover, proteins can maintain their individual structure by balancing attractive and repulsive interactions between them [26]. The extent of aggregation largely depends on extrinsic factors (e.g., temperature, ionic strength and $\mathrm{pH}$ ) arising from environmental and processing conditions. Aggregation is a prerequisite for the formation of protein micro- and nanosystems; when properly controlled and engineered, that may result in materials with novel functionalities [32, 37].

Protein micro- and nano-delivery structures can be formed from a single protein or from a mixture of proteins. Balandrán-Quintana et al. [38] produced nanoparticles from $\alpha$-lactalbumin with an average diameter of $404 \pm 34 \mathrm{~nm}$, an average inner diameter of $71 \pm 14 \mathrm{~nm}$ and average heights of $7 \pm 0.93 \mathrm{~nm}$. On the other hand, Monteiro et al. [39] used a mixture of two proteins (i.e., $\alpha$-lactalbumin and lysozyme) to obtain structures in the micro- and at nano $(61 \pm 2.3 \mathrm{~nm})$ scale level, depending on the environmental conditions (i.e., $\mathrm{pH}$ and heating treatment) used. These structures showed to be stable for 30 and 90 days when storage at 25 at $4{ }^{\circ} \mathrm{C}$, respectively.

\subsection{Lipids}

Lipids are generally referred as fats (in solid form) or oils (in liquid form) depending on their physical state at room temperature. These compounds are classified as nonpolar (e.g., triacylglycerol and cholesterol) or polar (e.g., phospholipids) lipids, causing significant differences in their solubility and functional properties $[18,30]$.

The physicochemical properties of lipids control their microstructural characteristics, colloidal stability, as well as rheological and moisture barrier properties. A decrease in the length of their hydrocarbon chain attached to the glycerol backbone, or an increase in the degree of unsaturation of the fatty acid chains, lowers their melting point and decreases their moisture barrier properties [16].

Lipid-based delivery systems confer a series of advantages such as the ability to retain materials with different solubilities, in particular those with high hydrophobicity, thus protecting a bioactive compound from biological and chemical degradation, while providing stability during storage. Moreover, they may enhance the encapsulation efficiency of hydrophobic bioactive compounds, thus increasing its bioavailability and reducing its potential toxicity [10]. Recent articles addressing the physicochemical properties of distinct lipid-based delivery systems are made available elsewhere [40-43].

Phospholipids are a class of lipids that are essential for human health and the main constituents of cellular membranes. They are biocompatible materials and have amphiphilic nature, which permits self-assembly, emulsifying and wetting properties. Hence, such compounds have demonstrated potential to encapsulate hydrophobic and hydrophilic bioactive compounds [44]. Ramadan [45] showed that when phospholipids are associated to polyphenols, they have more antioxidant activity than those that appeared isolated.

Tamjidi et al. [46] selected oleic acid and glyceryl behenate, from different lipid mixtures, for developing astaxanthin-loaded nanostructured lipid carriers. This lipid complex showed to be physically stable for delivering astaxanthin and other lipophilic compounds, into aqueous-based foods and beverages.

\subsection{Different combinations of bio-based materials}

Some applications may require the properties of different materials and, thus, the combination of different bio-based materials can be performed in order to take advantage of a multi-functional system. The appropriate combination of bio-based materials (e.g., proteins, polysaccharides, lipids and other materials) can improve the properties of micro- and nano delivery systems in terms of mechanical, thermal and barrier resistance, encapsulation efficiency, stability and bioavailability of bioactive compounds, when compared with those obtained by using a single material [47].

The combination of proteins and polysaccharides has been reported in several studies [48-53] as a suitable solution for the development of efficient oral delivery systems. Proteins have high nutritional properties, high capacity to form gels and they are easily hydrolyzed by digestive proteases, while polysaccharides (e.g., alginate, pectin, dextran and chitosan) possess high stability under harsh gastric conditions (i.e., are resistant to digestive enzymes) and display a high adhesiveness to the intestinal mucosal surface [54].

Moreover, the opposite electrical charges between proteins and polysaccharides affected by environmental conditions, contribute to associative interactions between both biopolymers trough electrostatic attraction. For instance, a polymeric system composed by a mixture of an anionic polysaccharide and a globular protein (at different specific $\mathrm{pH}$ values) can be formed; when the $\mathrm{pH}$ of the protein solution is above its $\mathrm{pI}$, there are repulsive electrostatic forces between protein and the anionic groups of the polysaccharide structure. However, if the $\mathrm{pH}$ of protein solution is below its $\mathrm{pI}$, the cationic regions of the protein surface can interact with the anionic groups of the polysaccharide chain, thus leading to weak electrostatic interactions and to the formation of soluble complexes. At lower pH values, the content of cationic groups on the proteins surface increases, which leads to greater electrostatic attraction between protein and anionic polysaccharides, thus resulting in charge neutralization and protein-polysaccharide complex formation. At pH values below the pKa of the anionic groups on the polysaccharide chain, the attractive interactions between the protein and polysaccharide molecules may weaker, which may result in complex dissociation $[55,56]$.

Ding and Yao [57] developed a soy protein/soy polysaccharide complex nanogel for encapsulation of folic acid intended to food and beverage applications. This delivery system was able to protect the folic acid from heat, light and oxygen in acidic conditions, while the surface of the nanogel, with polysaccharide nature, enabled its dispersion in acidic conditions.

\section{Bioactive compounds}

The development of modern biology, chemistry, molecular biology and biochemistry enabled the isolation of bioactive compounds, as well as the study of their interactions with the human body. Bioactive 
compounds are molecules that provide several benefits to human health by preventing or retarding the appearance of diseases through e.g., antioxidant, anti-inflammatory or anticancer activities. Therefore, the properties of bioactive compounds should be preserved until the exact moment and specific site where they will be used $[12,55]$.

Bioactive compounds such as antioxidants, antimicrobials, vitamins, probiotics, prebiotics, minerals, nutrients and polyphenols are not added in their pure state to food matrices, due to their susceptibility to physical, chemical and enzymatic degradation (and in some cases, due to their low water solubility), during processing, transportation and storage. The performance of these substances can be highly affected by light, heat, water and oxygen exposure, which may compromise its activity and shelf life. Moreover, the degradation of such compounds can cause off-flavor, off-colors or even carcinogenic residues; for instance some micronutrients, such as iron [58] and zinc [59] can react with other components in a way that their bioactivity and stability is compromised. Therefore, their encapsulation is of utmost importance to allow their incorporation in high water content food products, while preserving their bioavailability and preventing the aforementioned undesired effects [7,60].

The addition of encapsulated compounds (i.e., in a protected form) to food products can overcome some nutritional losses that frequently occur during food processing and storage; thus conferring protection and allowing its better absorption in the small intestine until they reach the bloodstream $[7,9,10]$.

The main bioactive compounds that have been used in food products for health promoting and/or disease preventing purposes are discussed below.

\subsection{Antioxidants}

Free radical and nitrogen species can be produced in the human body by various endogenous systems, through the exposure to different physiochemical conditions or through some pathological states. These species are considered one of the major causes of many current diseases, including diabetes and cardiovascular diseases.

Antioxidants can be obtained from natural sources such as vegetables, fruits, leaves, oilseeds, cereal crops and herbs and play an imperative role in providing protection against free radical and nitrogen species [61,62].

Phytochemicals are a large group of plant-derived compounds, including polyphenols, flavonoids, isoflavones, resveratrol and carotenoids that have high antioxidant and anti-inflammatory activity, thus providing several health benefits [63]. In many cases, phytochemicals need to be encapsulated in order to prevent undesired sensory properties (e.g., off-flavors and odors) in food products, thus permitting their use at higher concentrations without causing adverse effects to consumers [9]. The main physicochemical properties of plant extracts have been recently reviewed by Armendáriz-Barragán et al. [64]. Moreover, the main challenges associated to the encapsulation of antioxidants and the potential techniques to improve their bioavailability in different delivery systems were comprehensive reviewed elsewhere [65-68].

Curcumin is a fat-soluble polyphenol that has received an increased interest by the scientific community because it possesses significant antioxidant and anticarcinogenic activities, essentially due to the presence of two phenolic groups and a $\beta$-diketone moiety that all conjugated have the ability to scavenge reactive oxygen and nitrogen free radicals [69]. Benzaria et al. [70] showed that curcumin was successfully encapsulated into phosphocasein, being such system able to protect curcumin against harsh gastric conditions (i.e., it was resistant to pepsin digestion) and release it in the small intestine (i.e., it was degraded by pancreatin) where it is absorbed.

Lutein is a naturally occurring fat-soluble phytochemical that belongs to the carotenoids group. This antioxidant compound has important biological functions including the ability to prevent the development of cataracts and arteriosclerosis. However, in the food industry, its application is limited since it is highly unstable in the presence of undesired oxygen, light and temperature conditions. Its encapsulation may represent a suitable solution to overcome this issue [71].

Anthocyanins are water-soluble phytochemicals that belong to the flavonoids group and are important antioxidant compounds, responsible for color in several fruits. These bioactive compounds show stability at acidic $\mathrm{pH}$ values (e.g., $\mathrm{pH} 3$ ), and have low stability when subjected to neutral pH conditions. However, the large majority of food products do not have an acidic $\mathrm{pH}$, thus their encapsulation may allow overcoming this limitation [72]. Betz et al. [73] showed that the microencapsultion of blueberry, which is a rich source of anthocyanins, in whey protein hydrogel prevented their degradation at neutral pH (i.e., pH 6.8) conditions in comparison with non-encapsulated blueberry.

\subsection{Antimicrobials}

Antimicrobial compounds have a fundamental role in controlling the development and proliferation of pathogenic microorganisms in food products. Among all antimicrobial compounds, enzymes (e.g., lactoperoxidase and lysozyme), polysaccharides (e.g., chitosan), bacteriocins (e.g., nisin) and more recently, herbs, spices, essential oils (e.g., terpenes), alcohols, ketones, phenols, acids, aldehydes and esters have been commonly used for controlling the microbial growth [62, 74]. The structural and physicochemical properties of different microand nanosystems, as potential carriers for antimicrobials in food products, were comprehensively reviewed elsewhere $[75,76]$.

Essential oils arose an increasing interest by the food industry players because they are natural compounds obtained by plant extracts and they have demonstrated a significant antimicrobial activity, as well as a wide range of health benefits without known toxicity or sideeffects. However, their application in food products has limitations due to their poor solubility in water, high volatility and reactivity, and unpleasant aroma. Therefore, encapsulation appears to be a promising solution to solve these issues [62].

Donsì et al. [77] showed that the encapsulation of D-limonene into a nanoemulsion, formulated with sunflower and palm oils preserved the antimicrobial activity of this essential oil and displayed an inhibitory effect against Lactobacillus delbrueckii, Saccharomyces cerevisiae and Escherichia coli. Moreover, when it was applied in pear and orange juices, it proved to be more efficient than D-limonene in free form.

In a study conducted by Liang et al. [78], peppermint oil, used as an antimicrobial compound, was encapsulated in a nanoemulsion composed of medium-chain triacylglycerol. The authors demonstrated that the bioactive delivery system displayed a good stability (i.e., during 30 days of storage) and a prolonged antimicrobial activity against Listeria monocytogenes and Staphylococcus aureus, suggesting that it could be used to extend the shelf life of aqueous food products.

Moreover, Shah et al. [79] showed that delivery systems encapsulating eugenol into whey protein/maltodextrin nanocapsules exhibited antimicrobial activity against several E. coli 0157:H7 strains, indicating that it can be incorporated into food products to prevent bacterial growth.

\subsection{Vitamins}

Vitamins are bioactive compounds whose consumption is essential for growth, development and normal maintenance of the human body. These compounds cannot be naturally produced by the human body (except vitamin $\mathrm{D}$ and $\mathrm{B}_{3}$ ) and, consequently, they must be obtained from external sources [14].

The nutritional deficiencies in vitamin uptake can be caused by inadequate ingestion or utilization, poor absorption, increased excretion or destruction in the body, or even due to increased needs, which can 
lead to the development of certain diseases (e.g., cancer, and cardiovascular and eye degenerative diseases) [80].

Vitamins are classified as water-soluble (e.g., complex of vitamin $B$, including vitamin $B_{1}, B_{2}, B_{3}, B_{5}, B_{6}, B_{7}, B_{9}, B_{12}$ and vitamin $C$ ), or fatsoluble (e.g., vitamin A, D, E and $\mathrm{K}$ ). Vitamins are susceptible to degradation during processing, storage and until the moment of their absorption in the GI tract, due to a variety of factors (e.g., exposure to inadequate light, oxygen, temperature, $\mathrm{pH}$ or enzymatic conditions). Therefore, vitamin stability is an important parameter that should be considered when these compounds are added to food products. For instance, fat-soluble vitamins and vitamins $C, B_{1}, B_{2}$ and $B_{7}$ have poor oxidation stability, so they should be protected from heat, oxygen, metallic ions (especially from $\mathrm{Fe}^{2+}$ and $\mathrm{Cu}^{2+}$ ), polyunsaturated lipids undergoing peroxidation and UV light [81]. The potential of different micro- and nanosystems as carriers for lipophilic and hydrophilic vitamins, as well as the main safety issues associated have been deeply discussed in the literature [82-84].

Pezeshki et al. [85] successfully encapsulated vitamin A (encapsulation efficiency of 98.5\%) in a nanostructured lipid delivery system composed of caprylic/capric triglycerides, and observed a good stability of these systems during storage at $25{ }^{\circ} \mathrm{C}$ during 2 months. In another work, Madalena et al. [86] showed that vitamin $B_{2}$ was successfully encapsulated (i.e., efficiency of 26\%) into $\beta$-lactoglobulin nanohydrogels and released (i.e., 78\%) in the small intestine (throughout an in vitro GI assay), where its absorption occurs.

\subsection{Probiotics and prebiotics}

Probiotics are living microorganisms that, upon ingestion of a sufficient amount i.e., $10^{6}$ colony-forming units per gram (CFU/g) of intestinal content, promote beneficial physiological effects to the host [87]. Currently, probiotics are widely used during the production of functional food products, mainly in dairy products, with the purpose of enhancing the human health. However, when these compounds are used for health improving purposes, it is imperative that a minimum of $10^{6} \mathrm{CFU} / \mathrm{g}$ of intestinal content of probiotic bacteria are present in the final food product, at the expiration date [88,89].

The benefits associated to the ingestion of probiotic bacteria include the prevention and shortening of diarrhea and respiratory tract infections; the attenuation of lactose intolerance symptoms; the treatment of food allergy and elimination of toxins and pathogens from ingested foods or in the GI tract, through its binding [90].

Lactobacillus and Bifidobacterium are the main genera of probiotic microorganisms used in food industry. These microorganisms are Grampositive lactic acid producing bacteria that constitute a major part of the normal intestinal microflora in animals and humans [91,92]. Bifidobacteria are particularly sensitive to stress during processing, showing a low survival rate during storage and consumption of food products. The application of probiotics in food products is not an easy process since part of the microorganisms may lose their viability before consumption [93] and during the digestion process. The harsh gastric conditions of the human stomach are a natural barrier in the host, which significantly reduces the level of living probiotic bacteria. Thus, their encapsulation may represent a solution for this issue [94]. The benefits of probiotics and prebiotics for human health, the possible synergistic interactions between those bioactive compounds and their encapsulation for controlled and targeted release in the GI tract has been recently reviewed by Sarao and Arora [95].

Sarkar [96] reported several possible strategies to improve probiotics viability; however, they pointed microencapsulation as the best option to overcome the aforementioned challenges. In this sequence, Ying et al. [53] maintained the viability of probiotics during storage using a microemulsion composed by sunflower oil, stabilized by whey proteins and starch, and produced by spray drying. This delivery system was initially formulated with $2 \times 10^{11} \mathrm{CFU} / \mathrm{g}$ of probiotics and maintained at a sufficient level (i.e., $10^{7} \mathrm{CFU} / \mathrm{g}$ ) of viable cells after 5 weeks of storage.
In another study conducted by Priya et al. [97], Lactobacillus acidophilus were encapsulated into polyelectrolytes-chitosan-carboxymethyl cellulose microspheres produced through a layer-by-layer self-assembly technique. This system significantly increased the survival of encapsulated cells (both in simulated gastric and intestinal conditions), when compared with non-encapsulated cells.

Prebiotics (e.g., fructo-oligosaccharides, inulin, galactooligosaccharides and lactulose) are bioactive agents that are not digested in the upper part of the GI tract and promote the growth or activity of beneficial microorganisms (e.g., Lactobacillus spp. and Bifidobacterium spp) that colonize the large intestine, thus contributing to the well-being of their host $[98,99]$. These agents have potential to increase the bioavailability of nutrients and minerals, prevent GI infections and reduce the risk of ulcerative colitis, inflammatory bowel disease (e.g., irritable bowel syndrome) and colon cancer development $[92,100]$.

Krasaekoopt and Watcharapoka [87] encapsulated Lactobacillus acidophilus 5 and Lactobacillus casei 01 in alginate and chitosan microbeads with galactooligosaccharides and inulin as prebiotic agents, and added those microbeads to yogurt and fruit juice, used as food models. These authors concluded that galactooligosaccharides had a greater effect in probiotics viability, in comparison with inulin, thus improving probiotics growth in both yogurt and fruit juice.

Okuro et al. [101] studied the encapsulation of Lactobacillus acidophilus into solid lipid microparticles composed by palm oil with or without inulin and polydextrose as prebiotics. Results reveled that probiotic viability was improved in the formulation containing polydextrose, when evaluated during storage for 120 days, and in simulated digestion conditions (i.e., gastric and intestinal fluids).

Rajam and Anandharamakrishnan [102] encapsulated Lactobacillus plantarum in a microcapsule delivery system made from whey protein isolate, in either native or denatured form, with addition of fructooligosaccharide as prebiotic agent. The blend composed by fructooligosaccharide and denatured whey protein isolate, with mean diameter of $6.68 \mu \mathrm{m}$, showed higher encapsulation efficiency, stability and protection of probiotics, thus maintaining their viability during processing, storage, and under simulated gastric and intestinal conditions.

\subsection{Other bioactive compounds}

Natural flavorings are small molecules responsible for flavor that can be obtained from animal or vegetal sources through physical, enzymatic or microbiological processes. Incorporating flavoring substances in food products may contribute to enhance consumers' acceptance; however, its incorporation is a difficult task because, even in small amounts, flavors are usually sensitive, volatile and expensive molecules. Therefore, encapsulation is very important for the successful application of most flavors in food products, and thus to allow enhancing food sensory features [62]. Several examples of flavoring compounds such as oregano [103], rosemary [104], $\beta$-pinene [105], sweet orange [106] and lavender essential oils added, in encapsulated form, to food products are well described in the available literature.

Enzymes are bioactive compounds fundamental to catalyze specific biochemical reactions. Due to their relatively low stability and high cost, there are limitations associated to their use in food industry [32]. As an example, Jiang et al. [107] microencapsulated $\alpha$-amylase into microparticles of alginate, with a mean size of $11.8 \mu \mathrm{m}$, which helped enhancing enzymatic stability and activity.

Minerals are bioactive compounds essential to the human health that improve sensory and physicochemical food properties [108]. Iron, for example, is important to prevent anemia and to improve cognitive development [109]. However, this mineral may react with fatty acids, amino acids and vitamins present in food products, thus leading to their oxidation and, subsequently, reducing the nutritional value of foods. Therefore, iron encapsulation is crucial to prevent such undesired 
reactions [62]. Dubey and Windhab [58] successfully encapsulated iron in water-in-oil micro- and nanoemulsions prepared from palm stearin.

\section{Encapsulation techniques}

It is well known that the techniques involved in the synthesis and production of the structures may influence and modulate the overall properties of the delivery system. The production of such structures can be based in two different approaches: "bottom-up" and "topdown" [110]. The "bottom up" approach builds or grows large structures through atom-by-atom or molecule-by-molecule techniques. This approach includes chemical synthesis, self-assembly and positional assembly of molecules, which are influenced by several factors such as $\mathrm{pH}$, temperature, concentration and ionic strength. The "top-down" approach involves physical processing of the materials, which requires precise tools that allow size reduction and shaping of the structure for the desired application; an example is the homogenization technique, which is widely used to form emulsions and nanoemulsions [4,111].

The "bottom-up" approach has more control over the structure properties and conserves more energy than the "top-down" counterparts. However, both techniques have been optimized in order to achieve the desired properties for distinct food applications [112-115].

Bio-based micro- and nanosystems can be fabricated using different procedures, depending on the nature of the bioactive compound and of the encapsulating bio-based material (including their molecular weight, polarity, solubility, particle size distribution, encapsulation efficiency and shape) [16,116].

Due to the large diversity of available techniques that can be successfully employed in the production of micro- and nanosystems for encapsulation of bioactive compounds, intended for food applications, the main advantages, issues and differences are comprehensively discussed below and summarized in Table $1[10,12]$.

\subsection{Spray drying}

Spray drying (Figure 1 - A) is a mechanical dehydration process used in the food industry since the 1950s, and is the most extensively applied encapsulation method for food ingredients. This technique has the ability to convert a bio-based suspension into a powder, through a heat process, which causes rapid evaporation of the solvent and production of dried systems. The active compound (i.e., core) is homogenized with the matrix material (i.e., capsule) forming a dispersion; the mixture placed into the spray dryer is atomized in a hot chamber when passing through a nozzle, or a spinning wheel. Water evaporation occurs under a stream of hot air. Depending on the nature of the material, this technique can operate at temperatures between 150 and $300{ }^{\circ} \mathrm{C}$. The dry particles are then collected and separated in a cyclone [26,117].

Spray drying is a relatively simple process and offers several advantages as an encapsulation technique (e.g., low cost, high particle quality with good yield, small size, rapid solubility and good stability) [47,72]. However, this technique presents some limitations regarding its application for encapsulation of volatile or thermo-sensitive bioactive compounds. In fact, it produces particles with some degree of heterogeneity regarding particle size and morphology, as well as dispersions with high viscosity [32].

\subsection{Freeze drying}

Freeze drying (Fig. 1 - B) is a technique in which ice is sublimed to produce a gas, under pressure, where a small amount of heat is required [2]. The main steps of this technique are freezing, sublimation, desorption and storage [118]. It is an appropriate encapsulation technique for heat-sensitive materials and for preservation of materials for a long period of time [119-122] since the dehydration process occurs at low temperature, under vacuum. However, this technique is more expensive and requires a long dehydration time when compared with other techniques [123].

\subsection{Spray cooling}

Spray cooling (Fig. 1 - A), or spray chilling, is a spray drying-based concept that uses an atomization source, a particle production chamber and a sample collecting area. The main difference between the two techniques is in the particle production area, in which the particles are formed from the cooling and hardening of droplets rather than evaporation of a solvent [9]. Therefore, spray cooling may overcome some drawbacks of spray drying since it involves an opposite strategy: the bioactive compounds are dispersed in a liquefied matrix and atomized into a cool environment such as cool air. Usually, lipids with high melting point are used as matrix. At low temperatures, the lipid solidifies allowing the immobilization of labile compounds, such as mineral salts, enzymes, flavors and vitamins [17,24].

Alvim et al. [124] assessed the encapsulation of phytosterols into stearic acid and hydrogenated vegetable fat microparticles through spray cooling and obtained microparticles ranging from 13.8 to $32.2 \mu \mathrm{m}$ with a spherical shape. Okuro et al. [101] studied the co-

Table 1

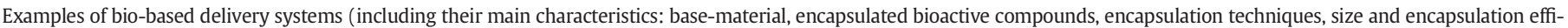
ciency) developed for food applications.

\begin{tabular}{|c|c|c|c|c|c|c|}
\hline Bio-based material & Encapsulating material & Bioactive compound & Encapsulation technique & Size & $\begin{array}{l}\text { Encapsulation } \\
\text { efficiency (\%) }\end{array}$ & References \\
\hline \multirow{3}{*}{$\begin{array}{l}\text { Polysaccharide-based } \\
\text { material }\end{array}$} & Zein & Curcumin & Antisolvent precipitation & $153 \mathrm{~nm}$ & 11.7 & {$[165]$} \\
\hline & Starch & Lycopene & Spray drying & NA & 29.7 & [244] \\
\hline & Hydroxypropyl cellulose & $\beta$-carotene & $\begin{array}{l}\text { Spray drying and fluid bed } \\
\text { coating }\end{array}$ & $63 \mu \mathrm{m}$ & NA & [136] \\
\hline \multirow[t]{3}{*}{ Protein-based material } & Whey protein & Bilberry extract & Emulsion & NA & NA & [73] \\
\hline & $\beta$-lactoglobulin & Thiosulfinate allicin & Freeze drying and spray drying & NA & NA & [220] \\
\hline & Whey protein & Astaxanthin & Spray-drying & 1 to $10 \mu \mathrm{m}$ & 58.7 & [245] \\
\hline \multirow[t]{2}{*}{ Lipid-based material } & $\begin{array}{l}\text { Lipid mixture of low trans hydrogenated } \\
\text { vegetable fat }\end{array}$ & Phytosterol mixture & Spray chilling & $32 \mu \mathrm{m}$ & 34.0 & [124] \\
\hline & $\begin{array}{l}\text { Liquid oil (Octyloctanoat) and solid lipid } \\
\text { (Precirol) }\end{array}$ & Vitamin A & Hot homogenization & $74-779 \mathrm{~nm}$ & 98.5 & [85] \\
\hline \multirow{6}{*}{$\begin{array}{l}\text { Combinations of bio-based } \\
\text { materials }\end{array}$} & Bovine serum albumin-Acacia gum & NA & Complex coacervation & $108 \mathrm{~nm}$ & NA & [246] \\
\hline & Gelatin-Pectin & Lycopene & Complex coacervation & NA & 93.2 & {$[125]$} \\
\hline & Maltodextrin- Arabic gum & $\begin{array}{l}\text { Barberry (Berberis vulgaris) } \\
\text { extract }\end{array}$ & Spray drying & NA & 96.2 & [247] \\
\hline & Chitosan-Cashew gum & Lippia sidoides oil & Spray drying & $405 \mathrm{~nm}$ & 70.0 & {$[248]$} \\
\hline & Maltodextrin-Whey protein concentrate & Flaxseed oil & Spray drying & $18 \mu \mathrm{m}$ & 60.0 & [249] \\
\hline & Whey protein isolate-Acacia gum & $\beta$-Carotene & Complex Coacervation & $140 \mu \mathrm{m}$ & 80.0 & {$[126]$} \\
\hline
\end{tabular}

Note: NA: Information not available 
SPRAY DRYING/ COOLING

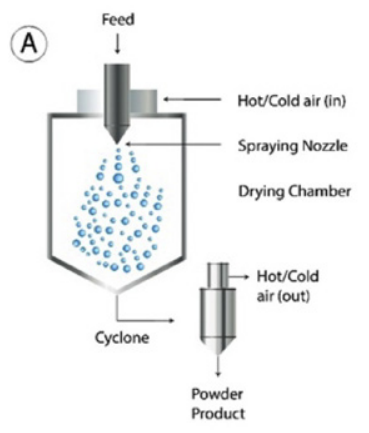

FLUID BED COATING

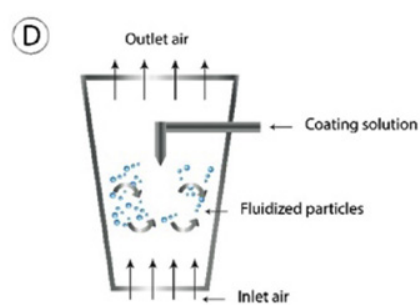

FREEZE DRYING

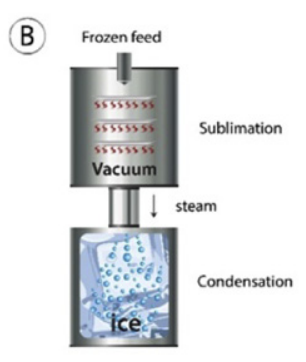

CO-EXTRUSION
COMPLEX COACERVATION

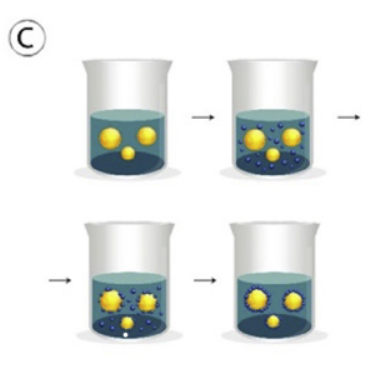

Fig. 1. Schematic representation of encapsulation techniques for food applications.

encapsulation of Lactobacillus acidophilus and polydextrose, probiotic and prebiotic bacteria, respectively, using spray chilling technique. These authors showed the formation of stable microsystems ranging from $66.1 \pm 3.9$ to $98.0 \pm 3.9 \mu \mathrm{m}$, with viability of microorganisms preserved during 120 days.

\subsection{Complex coacervation}

Coacervation is one of the most easily implemented techniques to produce micro- and nanosystems. It consists in an electrostatic attraction between opposite charged molecules to produce the encapsulating structure. The combination between molecules produces a complex, in which the system separates and forms two distinct phases, a polymerrich phase (coacervate) and a polymer-poor phase containing the solvent of the solution. This process is controlled by $\mathrm{pH}$, ion concentration and encapsulating material versus bioactive compound ratio [17,24,71]. This technique can be classified, according to the number of biopolymers used in this process, as simple (i.e., a single biopolymer is used) or complex (Fig. 1 - C) (i.e., two or more biopolymers are used) coacervation [10]. In the food industry, complex coacervation is widely used due to its ability to confer improved functional properties to controlled delivery systems, when compared with simple coacervation [2]; thus, more focus will be given to complex coacervation.

Complex coacervation has been widely used to encapsulate bioactive compounds such as lutein [71], lycopene [125], antioxidants [126-128], probiotics [129], flavors [130,131] and vitamins [132]. This technique has several advantages when compared with spray drying, since it offers a protective effect to high-value and unstable bioactive compounds (e.g., flavors, oils and vitamins). Moreover, complex coacervation (i) does not require high temperatures; (ii) has a high core loading level, a better shell integrity and a higher encapsulation efficiency; and (iii) the structures formed are water immiscible, which allows obtaining a controlled release of bioactive compounds [2].

\subsection{Fluid bed coating}

Fluid bed coating (Fig. 1 - D) is a technique where bioactive compounds are suspended in air and the encapsulating material is sprayed to form the encapsulation structures, in situ [17]. This technique permit several advantages such as low energy consumption, good reproducibility, final product standardization in terms of particle size distribution and shape, reduced operation time and cost (e.g., more than freeze drying technique) $[133,134]$. Recently, some bioactive compounds have been successfully encapsulated using the fluid bed coating technique, such as probiotics [134], ascorbic acid [135] and antioxidants [136]. However, high temperatures and direct exposure of the bioactive compounds to hot air, during several cycles, are some technical challenges that may limit their application to high sensitive compounds, once may led to their oxidation or degradation [137].

\subsection{Co-extrusion}

Extrusion is based on the injection of a bio-based solution into another solution to promote gelation [26], in order to produce a hard, dense and glassy structure, which is able to protect bioactive compounds from evaporation and oxidation during storage, enabling their controlled release [2]. Co-extrusion (Fig. 1 - E) is characterized by the extrusion of two or more biopolymers in order to obtain the final product. It may be used to produce spherical structures with a hydrophobic core and a hydrophilic or hydrophobic shell [88]. Co-extrusion is an appropriate method to microencapsulate oil through the creation of a shell barrier to enclose the oil core [138]. This technique is mainly used to encapsulate probiotics [139], antioxidants [138] and seed oils [140].

\subsection{Homogenization}

Different types of homogenization techniques have been used to develop colloidal dispersions, each one displaying its own characteristics (i.e., advantages and disadvantages) for applications. The most commonly used techniques e.g., high-shear mixer, high-pressure homogenization, microfluidization, and membrane and microchannel homogenizers, are briefly overviewed, whereas detailed information can be found elsewhere [141-143].

The high-shear mixer is widely used to form coarse emulsions having relatively large droplets, or to produce colloidal dispersions such as phase-separated biopolymer mixtures, known as water-in-water 
(W/W) or oil-in-water-in-water (O/W/W) systems [144]. These mixers are suitable for preparing emulsions from low- or intermediateviscosity fluids rather than from very high viscosity ones.

A high-shear mixer typically consists of a container where the oil, water, and other ingredients are placed, and a mixing head capable of generating intense disruptive forces by rapid rotation. This process breaks up the oil phase into tiny droplets that are then dispersed within the aqueous phase, thus leading to emulsion formation [141].

High-pressure homogenization is commonly used to produce conventional emulsions with small droplet size [10]. In this methodology, a premixed dispersion of oil and water phases passes through a narrow slit, between the homogenizing valves of the equipment, and the high shear stress produces small droplets [145].

Microfluidization uses high pressure to produce a current flow that forces the fluid to pass into microchannels, which reduces the particle size of emulsions. This technique is comparable to high-pressure homogenization, but the design of the channels for emulsion flow is different [10]. The major advantages of microfluidization are related with the wide range of particle sizes that can be obtained, the high reproducibility and the absence of toxic organic solvents. These techniques are the most frequently used to produce nanoemulsions at large scale [10, 146]. However, the resulting emulsion droplets are difficult to control because of the shear and pressure field variables introduced by such techniques [147,148]. Moreover, the aforementioned techniques are classified as high-energy processes because they require the use of mechanical devices to generate intense disruptive forces in order to separate the oil and water phases, thus leading to a high consumption of energy (ca. 90-99\%) for droplets formation [148].

Novel technologies have been developed and employed to produce monodisperse emulsions with lower energy consumption, such as membrane and microchannel homogenizers [149,150]. These techniques are particularly useful for producing particles with welldefined dimensions and internal structures $[151,152]$.

Membrane homogenizers can be used to form an emulsion directly from separate oil and water phases, or to reduce the size of the droplets in a coarse emulsion. In this technique, an emulsion can be obtained when one immiscible liquid (the disperse phase) is forced into another immiscible liquid (the continuous phase) through a solid membrane that contains small pores [147,149]. The size of the droplets in the emulsion formed is highly dependent on several factors such as the type and amount of emulsifier utilized, the membrane pore size, the oil-water interfacial tension, the pressure employed, and the flow rate of the continuous phase [147].

Microchannel homogenizers work on a similar way as membrane homogenizers, however the disperse phase is forced to pass through microchannels with well-defined forms to produce droplets [147,153]. This technique has been useful applied in the production of droplets with very narrow particle size distributions and with well-defined internal structures, such as core-shell [141].

\section{Micro- and nanosystems for entrapment of bioactive compounds}

Several delivery micro- and nanosystems have been developed for controlled release of bioactive compounds intended for food applications [4], and this section addresses the main bio-based delivery systems developed for such purpose.

The size, shape, and internal structure of these systems vary considerably depending on several factors including the method and materials used in their production. By definition, nanosystems are usually assumed to be $<100 \mathrm{~nm}$, however, in practice, the upper limit has been established up to $500 \mathrm{~nm}$, while considering colloids as nanosystems $[7,154,155]$. Instead, microsystems usually display sizes comprised between 1 and $1000 \mu \mathrm{m}$ [156]. The size is, therefore, an important feature of delivery systems since it affects their physicochemical stability, encapsulation and release characteristics, and biological activity $[12,155]$.

\subsection{Capsules}

Capsules (Fig. 2 - A) are one of the most widely studied delivery systems for bioactive compounds and they are defined as hollow vesicular structures that can entrap bioactive compounds by surrounding them with a biopolymer membrane, isolating the core (i.e., the bioactive compound) from the external environmental conditions [157]. These systems have the ability to homogeneously disperse or solubilize bioactive compounds inside its matrix, so it is not possible to differentiate the core from the matrix [10,157].

During capsule production various techniques can be applied, however the most commonly used is coacervation [4].

Capsules can be easily produced (i.e., do not require complex methodologies), present a high stability during storage, as well as in

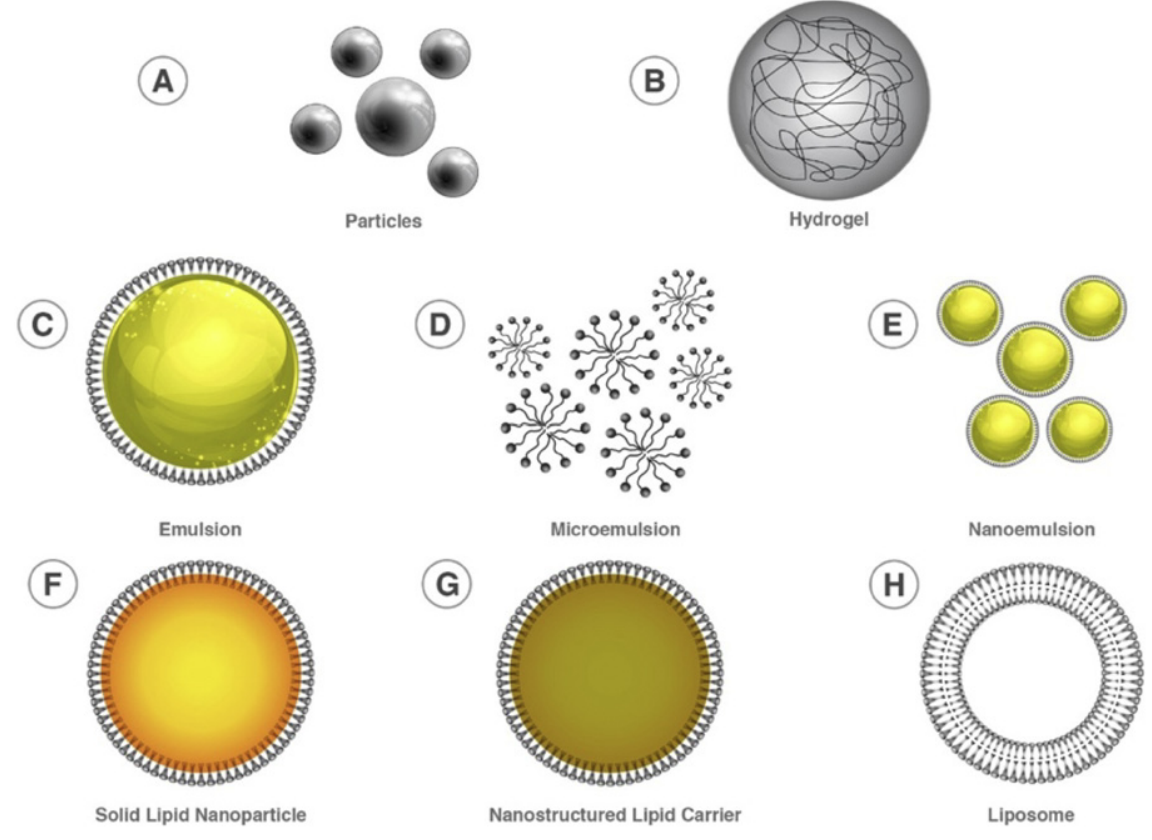

Fig. 2. Micro- and nano-delivery systems that may be used for encapsulation of bioactive compounds intended for food application. 
biological fluids, and significantly improve the stability of bioactive compounds entrapped into. Moreover, these systems allow a controlled release of bioactive compounds through a complete disintegration of its structure or by altering its porosity in response to external stimuli (i.e., changes in ionic strength, $\mathrm{pH}$ or temperature) [158].

\subsection{Hydrogel}

Hydrogel (Fig. 2 - B) is a three-dimensional network of hydrophilic polymeric molecules that can associate to each other by forming covalent or non-covalent (e.g., hydrogen bonds, van der Waals interactions and physical entanglements) interactions. This structure has the ability to swell ca. 30 times their initial size in the presence of water, and hold a large amount of water while maintaining its network structure [31].

The most commonly used strategy to prepare hydrogels includes gelation processes. During this phenomenon (i.e., gelation), the aggregation of polymeric chain groups occurs, through intermolecular bonds, which subsequently leads to the formation of a network structure. This process is denominated by "sol" and the continuous polymerization increases the extend of the ramification (i.e., increase in size of the polymer chain groups) and, consequently, decreases its solubility. The transition between the aggregation of polymeric molecules and the continuous cross-linking is called "sol-gel transition", or gelation, and the critical point where the gel is formed is denominated by "gel point" [20,159].

Appearance, texture, responsiveness and water-holding capacity are essential properties that are determined by the number, strength and morphology of the structural units and presence of hydrophilic moieties (i.e., hydroxyl, carboxyl, ethers, amines and sulphate groups) [15,32]. The mechanism of water absorption can be described as follows: when the dry hydrogel is hydrated, the polar hydrophilic groups are hydrated, creating the primary bond between water and the polymeric molecules. As the hydration continues, the polymeric structure increases physically, which exposes the hydrophobic groups that absorb additional water, thus leading to an equilibrium in the swelling level [4].

Therefore, a hydrogel has the ability to produce a response (i.e., swelling or shrinking) in virtue of some chemical (e.g., pH, solvent composition and ionic strength) and physical (e.g., temperature, electric or magnetic field, light and pressure) stimuli, making them important delivery systems of bioactive food ingredients [160,161]. For instance in pH-sensitive hydrogels, shrinkage occurs under gastric conditions; however, swelling occurs under intestinal conditions, which indicates that this delivery system can be used to protect a bioactive compound from the harsh conditions of the human stomach, releasing its content in the small intestine, so that nutrient absorption can occur [9].

\subsection{Lipid-based systems}

The enhancement of the bioavailability of orally ingested bioactive compounds is of utmost importance, particularly for compounds that present poor water solubility. Lipid-based systems appears as an appropriate alternative to solve this issue, due to their intrinsic physicochemical properties, diversity and biocompatibility [162]. These systems (e.g., emulsions, solid lipid nanoparticles, nanostructured lipid carriers and liposomes) have been extensively studied for food applications [85,163-171] and, therefore, a comprehensive review of such systems is presented below.

\subsubsection{Emulsions}

Emulsions (Fig. $2-\mathrm{C}$ ) are composed by two immiscible phases in which one (i.e., dispersed phase) is spread in small droplets in a solution (i.e., continuous phase) forming a stable phase combination. Bioactive compounds can be incorporated into the dispersed droplets and protected in the continuous phase from external environmental conditions $[172,173]$. These systems can be classified as oil-in-water $(\mathrm{O} / \mathrm{W})$, water-in-oil (W/O), liquid-in-liquid or solid-in-liquid emulsions. The emulsion characteristics and stability depend on i) the type of emulsifiers/surfactants used to stabilize the interface between phases, ii) its composition, iii) surfactant-to-oil ratio, iv) the presence of cosolvents and co-solutes, and (v) the homogenization conditions [174]. Oil-in-water emulsions are widely used to encapsulate and deliver lipophilic bioactive compounds, essentially due to its easy production process.

However, depending on the application, they have limitations such as weak physical stability (i.e., when exposed to high temperatures, or $\mathrm{pH}$ and ionic strength changes) during transportation, storage and use. This may reduce their protection properties against chemical degradation and consequently its bioactivity $[34,117,173]$.

Conventional emulsions (Fig. 2 - D) usually have a white opaque appearance under multiple scattering techniques, while nanoemulsions (Fig. 2 - E), with smaller droplets size (i.e., typically ranging from 10 to $100 \mathrm{~nm}$ ), are optically transparent. Hence, nanoemulsions are considered more appropriate as delivery systems for controlled release of bioactive compounds in beverages [175]. Usually, micro-, but in particular, nanoemulsions have good stability against droplet aggregation because the range of attractive van der Waals forces, between the droplets, decreases with particle size reduction [176].

Nanoemulsions can be used as delivery systems for several lipophilic compounds, such as essential oils (e.g., $\omega$-3-rich oils), polyphenolics (e.g., curcumin), antioxidants (e.g., quercetin), antimicrobials (e.g., thymol) and vitamins (e.g., vitamin A). Moreover, they may also associate to hydrophilic and amphiphilic bioactive components, that can be incorporated within the oil droplets, the continuous phase or the interfacial region of the oil-in-water nanoemulsions, depending of their nature [177].

Emulsions are mainly produced using high-energy techniques, which require special equipment that uses high mechanical energy (e.g., highpressure valve homogenizers, microfluidizers and sonicators), capable of generating intense disruptive forces that separate the oil and water phases, thus leading to the formation of oil droplets. However, lowenergy methodologies, mainly dependent on the intrinsic physicochemical properties of surfactants and oily phases (i.e., phase inversion and solvent demixing methods), can be also employed [40].

\subsubsection{Solid lipid nanoparticles}

Solid lipid nanoparticles (SLNs) (Fig. 2 - F) are oil-in-water emulsions in which the lipid phase has been either fully or partially solidified by a solid lipid, or a blend of solid lipids [4,178,179]. Common lipids used in this type of nanosystems include sunflower and palm oils [85,180,181].

SLNs present some limitations such as limited loading capacity and premature release of the entrapped compounds, which are associated with the poor solubility of bioactive compounds in the lipid melt and to high water content of the dispersions (i.e., 70-99.9\%), respectively, thus leading to nanosystems' instability during storage. When the lipid matrix consists of similar molecules (i.e., tristearin or tripalmitin), a perfect crystal with few imperfections is formed. Since the bioactive compounds are incorporated between the lipid layers and in crystal imperfections, a highly ordered crystal lattice may not enable a high encapsulation efficiency of compounds [42,162].

\subsubsection{Nanostructured lipid carriers}

Nanostructured lipid carriers (NLCs) (Fig. $2-\mathrm{G}$ ), are a combination between lipids in the liquid and solid state, where the overall solid content can be up to $95 \%$ of the total weight. NLC were developed to overcome the main limitations of SNLs, presenting a higher loading capacity and a sustained bioactive compound release profile (i.e., lowering the possibility of an early release during storage), because they display a low crystallinity index [162,182].

Aditya et al. [181] studied the bioavailability of quercetin in different nanosystems such as SLNs, NLCs and lipid nanoemulsions (LNE). These authors showed that loading efficiency of quercetin was higher when it was incorporated in NLCs or LNE, than in SLNs. This can be attributed to the formation of less ordered lattice defect in NLC and LNE with more 
space for incorporate quercetin [181]. However, in the food industry, the application of NLCs has some limitations such as: (i) the relatively low purity of the bio-based materials used, when compared with those of the pharmaceutical industry; and (ii) the different $\mathrm{pH}$ values, osmotic pressure and ionic strength of food products can lead to agglomeration and flocculation of NLCs [163].

\subsubsection{Liposomes}

Liposomes (Fig. $2-\mathrm{H}$ ) are spherical vesicles composed by a membrane-like phospholipid bilayer surrounded by an aqueous medi$\mathrm{um}$. This delivery system is formed by a combination between surfactants and water, under low shear forces. The ability to entrap hydrophilic, hydrophobic and amphiphilic bioactive compounds makes them suitable carriers to be applied to food products $[10,42,60]$. However, their high cost associated to their production, low loading capacity, fast release rates and relatively high instability, during storage, still limiting their application in the food industry [183].

\subsection{Comparison between distinct micro- and nanosystems}

Lipid-based systems, including emulsions and solid lipid nanoparticles have been developed to carry and deliver hydrophobic compounds, such as oil-soluble flavors, colors, preservatives, vitamins and nutraceuticals [8, 184]. Lipossomes have the ability to entrap, protect and release hydrophilic, hydrophobic and amphiphilic bioactive compounds. However, some challenges exist which limit their application in the food industry, namely: i) the difficultly of production at an economically feasible and technically reliable large scale; ii) the poor physical stability when subjected to distinct conditions present in complex food matrices; and iii) the poor encapsulation efficiency and loading capacity [185]. Capsules and hydrogels can be designed to spontaneously load either hydrophilic or hydrophobic bioactive compounds through electrostatic, van der Waals and/or hydrophobic interactions between the bioactive compound and the encapsulating matrix [186]. These systems also permit a controlled release of bioactive compounds through a partial or complete disintegration of their structure in response to external stimuli (i.e., changes in temperature, $\mathrm{pH}$, ionic strength or enzymatic conditions) [4].

Regarding encapsulation techniques, emulsions are usually produced through high-energy methods, which require devices that use high mechanical energy input. Low-energy approaches can be also employed, but are based on the spontaneous formation of oil droplets in surfactant-oil-water mixtures when the composition or temperature of the system is changed [40]. Capsules can be easily produced through different methodologies such as coacervation, polymerization or selfassembly, but depending on the technique employed, they may require the intervention of external agents, which may turn the production process more complex and expensive [4,7]. On the other hand, hydrogels permit overcoming some drawbacks inherent to other nanosystems such as the case of lipid-based systems or capsules, once they can be produced with relatively low cost materials and usually employ simple preparation methods without requiring addition of extra components. Moreover, these systems usually allow higher encapsulation and loading yields $[4,7]$.

\section{Behavior of micro- and nanosystems and bioavailability of bioactive compounds}

The human digestive system (HDS) is a complex, multi-phase (i.e., oral, stomach, small intestine and large intestine compartments) biologic process in which food products undergo a series of processes that transform them into smaller and more basic components, in order to be absorbed (mostly in the small intestine) and reach the bloodstream. Therefore, studying the different physicochemical conditions of the HDS and their impact on food products is of utmost importance [4, 145]. The summary of the main physicochemical conditions is shown in Fig. 3.

In the oral cavity, food products are submitted to a neutral environment (i.e., pH 7.0), mechanical stress (i.e., chewing) and to saliva (where they are dissolved), which contains some important enzymes (e.g., $\alpha$-amylase) and proteins (e.g., mucins). Subsequently, food passes to the gastric compartment, where it is submitted to mechanical agitation (peristaltic movements) and acidic environment (i.e., $\mathrm{pH}$ ranges from 1.0 to 3.0), due to $\mathrm{HCl}$ secretion. Furthermore, important enzymes (e.g., pepsin and gastric lipase) interact with food products in order to break them down into their basic constituents, so that they can be absorbed in the small intestine. The duodenum is the main absorption site in the small intestine. At this stage, food suffers an increase in the environmental pH (from 6.0 to 7.5 ) so that gastric enzymatic activity is interrupted. In this compartment, foods interact with inorganic salts, bile salts and other enzymes (e.g., pancreatic lipase, trypsin, chymotrypsin, among others) to further break down food into smaller constituents. Here, the nutrients can be absorbed once enzymatic digestion is finished $[145,158,187]$. The non-absorbed digestion products pass to the large intestine, in which water content, electrolytes and bile salts are absorbed. At this compartment, polysaccharides and proteins suffer a fermentation process by the colonic microbiota and the resulting waste products are then excreted from the human body $[188,189]$.

Due to the HDS complexity, many in vitro digestion models (static and dynamic) were created in order to study the food behavior when submitted to GI conditions.

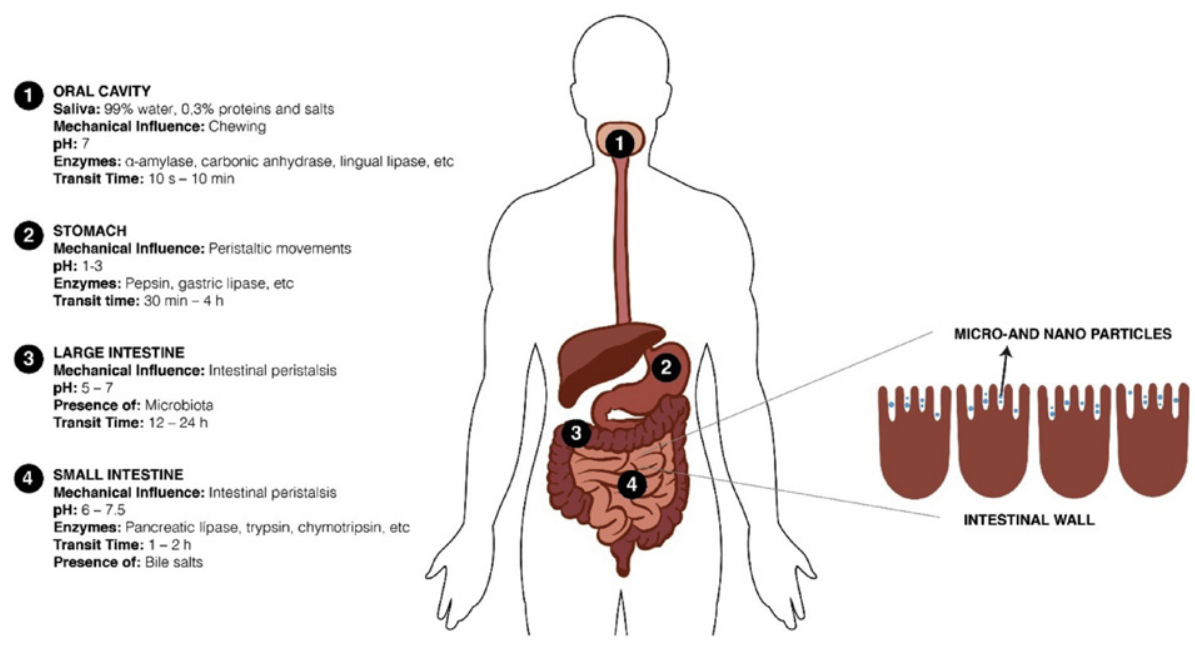

Fig. 3. Schematic diagram representing the main physiological conditions present in the human digestive system. 
Table 2

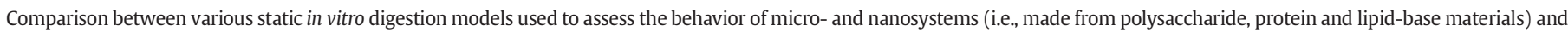
of the bioavailability of bioactive compounds entrapped into.

\begin{tabular}{|c|c|c|c|c|c|}
\hline Bio-based delivery systems & Conditions & Oral Phase & Stomach & Small Intestine & Reference \\
\hline \multirow{25}{*}{$\begin{array}{l}\text { Polysaccharide-base delivery } \\
\text { systems }\end{array}$} & Delivery system & \multicolumn{3}{|l|}{ Alginate microgels } & \multirow[t]{5}{*}[194]{} \\
\hline & $\mathrm{pH}$ & \multirow[t]{4}{*}{ NA } & $2.0(1 \mathrm{M} \mathrm{HCl})$ & $7.5(\mathrm{NA})$ & \\
\hline & Secretion & & $\begin{array}{l}\text { Simulated gastric fluid }+ \\
\text { pepsin }(4500 \mathrm{U} / \mathrm{mL})\end{array}$ & $\begin{array}{l}\text { Simulated intestinal fluid }+ \\
\text { pancreatin }(1.0 \%)+\text { bile salts } \\
(0.5 \%)\end{array}$ & \\
\hline & Duration (min) & & 120 & 60 & \\
\hline & Stirring & & Yes (100 strokes/min) & Yes (100 strokes/min) & \\
\hline & Delivery system & \multicolumn{2}{|l|}{ Chitosan nanoparticles } & & \multirow{5}{*}[195]{} \\
\hline & $\mathrm{pH}$ & \multirow[t]{4}{*}{ NA } & $1.5-2.0(9 \mathrm{M} \mathrm{HCl})$ & $7.0\left(1 \mathrm{M} \mathrm{NaHCO}_{3}\right)$ & \\
\hline & Secretion & & $\mathrm{NaCl}$ buffer $0.5 \%(\mathrm{w} / \mathrm{v})$ & & \\
\hline & Duration (min) & & 60 & 120 & \\
\hline & Stirring & & Yes (150 rpm) & Yes (90 rpm) & \\
\hline & Delivery system & \multicolumn{2}{|l|}{ Chitosan and alginate } & & \multirow[t]{5}{*}[250]{} \\
\hline & $\mathrm{pH}$ & $6.8(\mathrm{NA})$ & $1.2(1 \mathrm{M} \mathrm{HCl})$ & $7.0(1 \mathrm{M} \mathrm{NaOH})$ & \\
\hline & Secretion & $\begin{array}{l}\text { Simulated saliva fluid }+ \text { mucin } \\
(5 \mathrm{~g} / \mathrm{L})\end{array}$ & Simulated gastric fluid & $\begin{array}{l}\text { Simulated intestinal fluid }+ \\
\text { bile extract }(187.5 \mathrm{mg} / \mathrm{mL})+ \\
\text { pancreatic lipase }(60 \mathrm{mg} / \mathrm{mL})\end{array}$ & \\
\hline & Duration (min) & 10 & 60 & 120 & \\
\hline & Stirring & Yes (100 rpm) & Yes (100 rpm) & Yes (100 rpm) & \\
\hline & Delivery system & \multicolumn{2}{|l|}{ Alginate microcapsules } & & \multirow[t]{5}{*}{ [251] } \\
\hline & $\mathrm{pH}$ & \multirow[t]{4}{*}{ NA } & $3.0(0.1 \mathrm{~N} \mathrm{HCl})$ & $7.0\left(0.1 \mathrm{~N} \mathrm{NaHCO}_{3}\right)$ & \\
\hline & Secretion & & Pepsin $(3 \mathrm{~g} / \mathrm{L})$ & $\begin{array}{l}\text { Pancreatin }(1 \mathrm{~g} / \mathrm{L})+\text { bile salts } \\
(4.5 \mathrm{~g} / \mathrm{L})\end{array}$ & \\
\hline & Duration (min) & & 60 & 60 & \\
\hline & Stirring & & NA & NA & \\
\hline & Delivery system & \multicolumn{2}{|c|}{ Gellan microgel coated with chitosan } & & \multirow[t]{5}{*}[252]{} \\
\hline & $\mathrm{pH}$ & \multirow[t]{4}{*}{ NA } & $2.0(6 \mathrm{M} \mathrm{HCl})$ & $5.3-7.0\left(0.9 \mathrm{M} \mathrm{NaHCO}_{3}\right)$ & \\
\hline & Secretion & & $\begin{array}{l}\text { Porcine pepsin }(40 \mathrm{mg} / \mathrm{mL} \text { in } \\
0.1 \mathrm{M} \mathrm{HCl}) \text { at a ratio of } \\
0.5 \mathrm{~g} / 100 \mathrm{~mL} \text { of sample }\end{array}$ & $\begin{array}{l}\text { Pancreatin }(2 \mathrm{mg} / \mathrm{mL})+ \\
\text { porcine bile extract } \\
(12 \mathrm{mg} / \mathrm{mL})\end{array}$ & \\
\hline & Duration (min) & & 60 & 120 & \\
\hline & Stirring & & Yes (NA) & Yes (NA) & \\
\hline \multirow[t]{20}{*}{ Protein-base delivery systems } & Delivery system & \multicolumn{2}{|l|}{ Cruciferin nanoparticles } & & \multirow[t]{5}{*}{ [197] } \\
\hline & $\mathrm{pH}$ & \multirow[t]{4}{*}{ NA } & $1.2(\mathrm{NA})$ & $\begin{array}{l}7.4 \text { ( } 200 \mathrm{mM} \text { phosphate } \\
\text { buffer) }\end{array}$ & \\
\hline & Secretion & & $\begin{array}{l}\text { Simulated gastric fluid }+ \\
\text { pepsin }(0.5 \mathrm{mg} / \mathrm{mL})\end{array}$ & $\begin{array}{l}\text { Simulated intestinal fluid }+ \\
\text { pancreatin }(0.5 \mathrm{mg} / \mathrm{mL})\end{array}$ & \\
\hline & Duration (min) & & 120 & NA & \\
\hline & Stirring & & Yes (100 rpm) & Yes (100 rpm) & \\
\hline & Delivery system & \multicolumn{2}{|l|}{$\beta$-lactoglobulin-IgE } & & {$[253]$} \\
\hline & $\mathrm{pH}$ & NA & 2.0 (NA) & $7.0-6.5\left(1 \mathrm{M} \mathrm{NaHCO}_{3}\right)$ & \\
\hline & Secretion & & $\begin{array}{l}\mathrm{NaCl}(35 \mathrm{mM})+\text { pepsin }(3440 \\
\mathrm{U} / \mathrm{mg})\end{array}$ & $\begin{array}{l}\mathrm{CaCL}_{2}(7.6 \mathrm{mM})+\text { bis-Tris } \mathrm{pH} \\
6.8(20.3 \mathrm{mM})+\text { bile salts } \\
(12.3 \mathrm{mM})+\text { lipase } \\
(28.4 \mathrm{U} / \mathrm{mg})+ \\
\alpha \text {-chymotrypsin }(0.44 \mathrm{U} / \mathrm{mg}) \\
+ \text { trypsin }(34.5 \mathrm{U} / \mathrm{mg})+ \\
\text { colipase }(\text { ratio of } 1: 895 \mathrm{w} / \mathrm{w})\end{array}$ & \\
\hline & Duration (min) & & 60 & NA & \\
\hline & Stirring & & Yes (NA) & Yes (NA) & \\
\hline & Delivery system & Whey protein isolate & & & {$[218]$} \\
\hline & $\mathrm{pH}$ & $7.4\left(4 \times 10^{-4} \mathrm{mM} \mathrm{NaOH}\right)$ & $1.2(0.15 \mathrm{M} \mathrm{HCl})$ & $7.4\left(4 \times 10^{-4} \mathrm{mM} \mathrm{NaOH}\right)$ & \\
\hline & Secretion & $\begin{array}{l}\text { Simulated saliva fluid }+ \\
\alpha \text {-amylase }(290 \mathrm{mg})+\text { uric } \\
\text { acid }(15 \mathrm{mg})+\text { mucin }(25 \mathrm{mg})\end{array}$ & $\begin{array}{l}\text { Simulated gastric fluid }+ \\
\text { pepsin }(3.5 \mathrm{~g})+\text { mucin }(3.0 \mathrm{~g})\end{array}$ & $\begin{array}{l}\text { Duodenal juice }+ \text { bile juice }+ \\
\text { pancreatin }(9.0 \mathrm{~g})+\text { lipase } \\
(1.5 \mathrm{~g})\end{array}$ & \\
\hline & Duration (min) & 5 & 120 & 120 & \\
\hline & Stirring & Yes (100 rpm) & Yes (100 rpm) & Yes (100 rpm) & \\
\hline & Delivery system & $\beta$-lactoglobulin & & & {$[196]$} \\
\hline & $\mathrm{pH}$ & NA & $1.2(0.15 \mathrm{M} \mathrm{HCl})$ & NA & \\
\hline & Secretion & & $\begin{array}{l}\text { Simulated gastric fluid }+ \\
\text { pepsin }(3.2 \mathrm{mg} / \mathrm{mL})\end{array}$ & & \\
\hline & Duration (min) & & 120 & & \\
\hline & Stirring & & Yes (agitation) & & \\
\hline Lipid-base delivery systems & Delivery system & Oil-in-water emulsion stabilized & with soy and pea protein isolate & & [199] \\
\hline & $\mathrm{pH}$ & NA & 2.0 (NA) & $7.0(\mathrm{NA})$ & \\
\hline & Secretion & & $\begin{array}{l}\text { Simulated gastric fluid }+ \\
\text { pepsin }(25,000 \mathrm{U} / \mathrm{mL})\end{array}$ & $\begin{array}{l}\text { Simulated intestinal fluid }+ \\
\text { pancreatin }(5.0 \mathrm{mg} / \mathrm{mL})+ \\
\text { phospholipase } \mathrm{A} 2(5.0 \mathrm{~mL} \text { of } \\
6.7 \mathrm{mg} / \mathrm{mL})+ \text { simulated bile } \\
\text { fluid }(0.4 \mathrm{mM} \text { bile salts and } \\
1 \mathrm{mM} \text { phospholipids })\end{array}$ & \\
\hline & Duration (min) & & 60 & 120 & \\
\hline & Stirring & & Yes (250 rpm) & Yes (250 rpm) & \\
\hline & Delivery system & Corn oil stabilized with Tween 2 & & & {$[254]$} \\
\hline
\end{tabular}


Table 2 (continued)

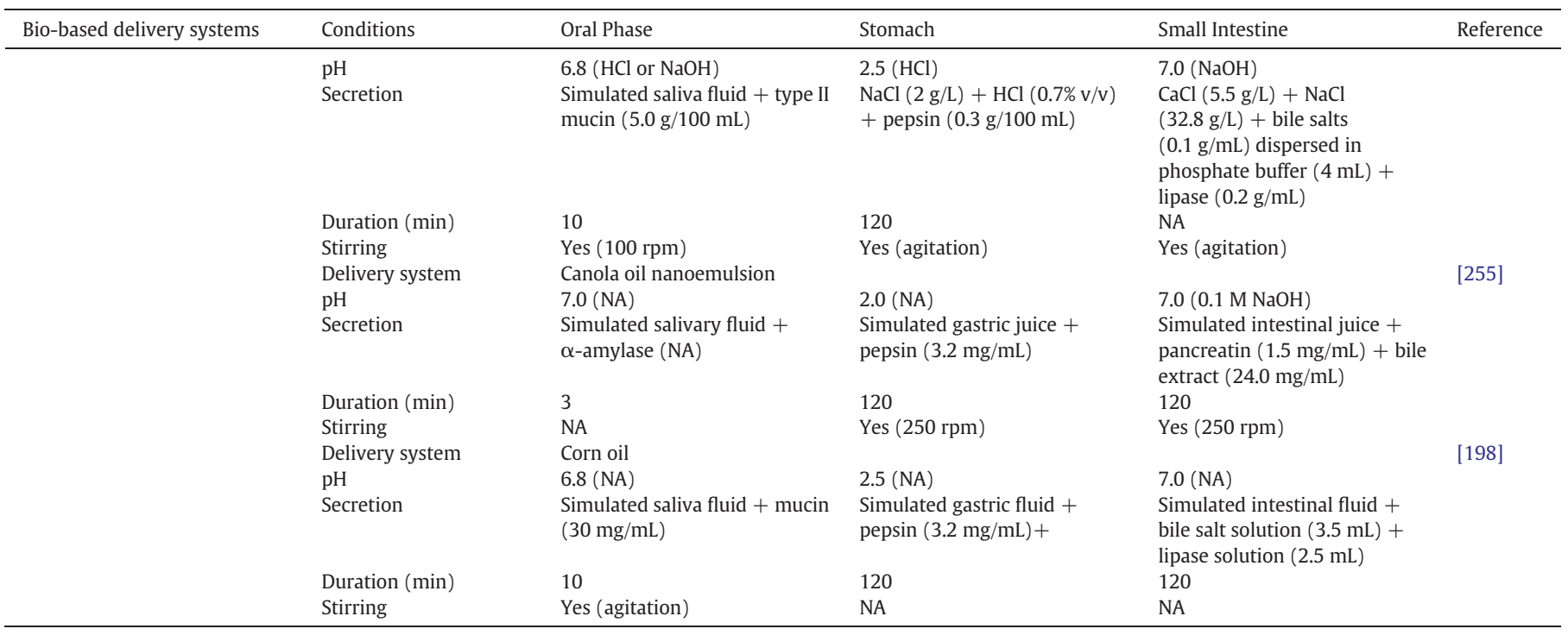

Note: All experiments were performed at $37^{\circ} \mathrm{C}$; NA: Information not available.

\subsection{In vitro digestion models}

In vitro models can be divided into static or dynamic digestion models, depending on their complexity. These systems are often used to provide some insight regarding the digestibility of controlled release systems and bioavailability of functional compounds [190]. Static models are practical and inexpensive models that allow the assessment of multiple samples. On the other hand, dynamic digestion models are complex multistage systems intended to mimic, as close as possible, the human digestion conditions, enabling the simulation of the physicochemical changes (i.e., pH transitions, enzyme secretion alteration and peristaltic movements) that occur during an in vivo digestion. In vitro experiments (i.e., both static and dynamic models) allow obtaining reproductive (without biological variations) and faster results in a more economical way. Moreover they require less manpower, are easy to perform, do not involve ethical issues and allow sampling at any time of digestion process, when compared with in vivo experiments [190,191].

\subsection{In vitro static digestion models}

Recently, several studies regarding the assessment of the behavior of micro- and nanostructured systems, as well as the release rates and bioavailability of bioactive compounds were performed using in vitro static digestion models. The main research results obtained until now are summarized in Table 2.

Table 2 shows that a wide variety of physicochemical conditions were used to simulate the physiological conditions of the human GI tract, demonstrating that there is a lack of agreement regarding the in vitro digestion models protocol. In fact, Alminger et al. [190] addressed this subject by referring that, usually, most of the in vitro digestion models derived from the method described by Miller et al. [192] and, thus, the physicochemical conditions of such studies are significantly different. However, these studies contribute with important insights regarding the understanding of the behavior of micro- and nanostructured systems under GI conditions. Recently, within the COST Infogest network, a general standardised and practical static digestion method based on physiologically relevant conditions has been proposed, aiming at uniformizing the existing protocols and the production of more comparable results [193].

Bokkhim et al. [194] and Madureira et al. [195] assessed the influence of GI conditions on alginate microgels and chitosan nanoparticles, respectively. Both concluded that alginate microgels and chitosan nanoparticles were suitable delivery systems for nutraceuticals. Peram et al. [196] and Akbari \& Wu [197] studied the influence of gastric and GI conditions on $\beta$-lactoglobulin ( $\beta$-Lg) (on native and heat-denaturated state) and cruciferin, respectively. They concluded that $\beta$ - Lg in native state and cruciferin were resistant to the gastric and GI conditions (i.e., $\mathrm{pH}$ and pepsin digestion), respectively, suggesting that both protein systems could be used as nano-delivery systems for bioactive compounds. Zhang et al. [198] showed that oil-in-water emulsions can increase the bioaccessibility of carotenoids from carrots, whereas Fernandez-Avila et al. [199] proved that oil-in-water emulsions protected their conjugated linoleic acid content during storage and in vitro digestion. These delivery systems (from polysaccharide, protein or lipid bio-based nature) showed to be suitable nutraceutical carriers, throughout the GI tract conditions, protecting their content until the appropriate release site.

Despite their simplicity and low cost, static in vitro models do not accurately simulate the complexity and the GI conditions in the HDS [190, 198]. Therefore, dynamic in vitro digestion models were created in order to overcome these limitations by simulating the dynamic conditions of the HDS (e.g., peristaltic movements) [158,190].

\subsection{In vitro dynamic digestion models}

In vitro dynamic digestion models are generally comprised by a multi-chamber apparatus (e.g., Fig. 4) that can better simulate the dynamic changes that are present in HDS [190].

TIM-1 (Fig. 4) is a dynamic in vitro digestion model developed by TNO Nutrition and Food Research (Zeist, the Netherlands), that comprises four consecutive glass containers simulating the stomach, duodenum, jejunum and ileum. Each glass compartment contains a flexible wall within its structure. All experiments are performed under constant temperature $\left(37^{\circ} \mathrm{C}\right)$, which is achieved by pumping water into the space between the glass containers and the flexible wall. This system also mimics the peristaltic movements of the HDS by alternating compression and relaxation of the flexible walls [200]. Moreover, this system allows the simulation of the intestinal absorption: the jejunum and ileum compartments are connected to filtration units (semi-permeable hollow-fibre devices with a molecular cut-off of $5 \mathrm{kDa}$ ) which allow the quantification of the bioaccessibility [201]. Non-bioaccessible fractions (ileal delivery) are collected at the end of ileum compartment and represent the unabsorbed material that will pass to the large intestine.

[202]Fondaco et al. [202] studied the lipid digestion of Human breast milk and a commercialized infant formula, by assessing free fatty acid 


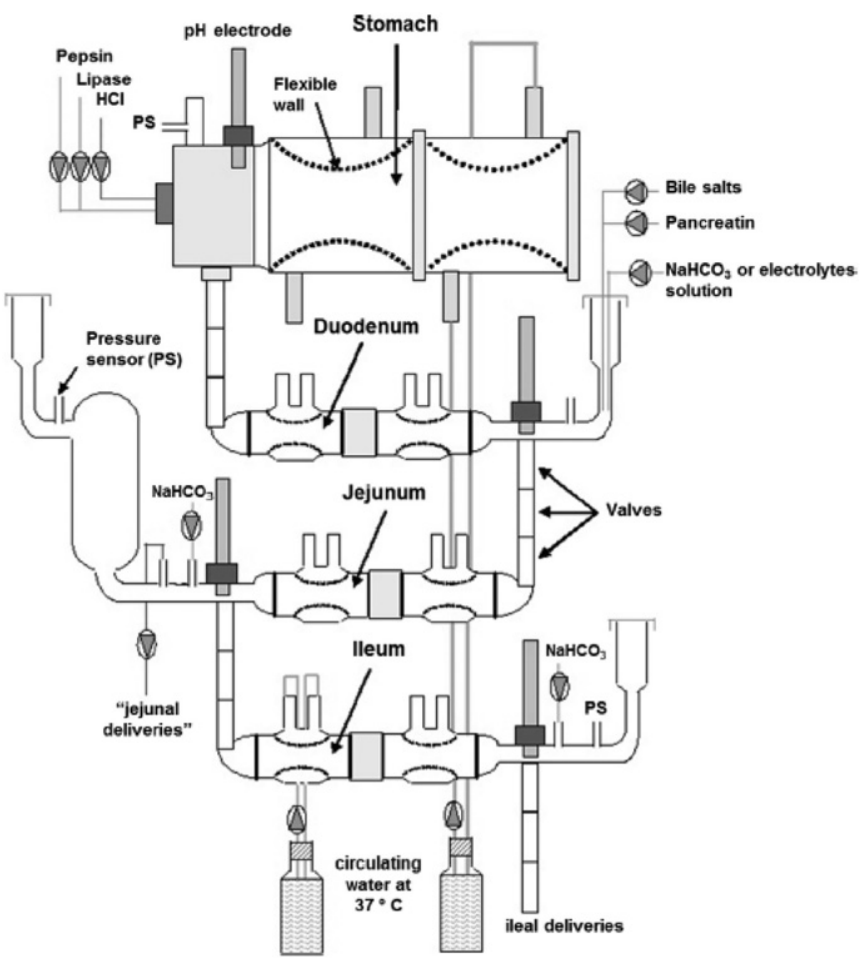

Fig. 4. Schematic representation of TIM-1 (Adapted from Villemejane et al. [200]).

bioavailability, using TIM-1 as an in vitro digestion model. They observed that the lipolysis rates were higher in Human breast milk when compared with the commercialized infant formula. Although, did not observed significant differences between breast milk and the commercialized infant formula regarding the free fatty acid bioavailability. Villemejane et al. [200] recently studied the effect of the enrichment of biscuits (i.e., addition of proteins and viscous fibers) in protein and starch digestion using TIM- 1 as the in vitro digestion model. They observed that the addition of proteins or fibers delayed or lowered proteolysis.

Ménard et al. [203] developed a dynamic in vitro digestion model (French National Institute for Agricultural Research - Institut National de la Recherche Agronomique) to study the digestion of food products under in vitro digestion conditions. This system is comprised by two digestion compartments in order to simulate the physiological conditions of the human stomach and small intestine (Fig. 5). Each chamber consists of a glass jacket, kept at $37^{\circ} \mathrm{C}$, equipped with sensory equipment (i.e., temperature, $\mathrm{pH}$ and redox sensors) and computer-controlled peristaltic pumps. Between the stomach and the small intestine compartment, a Teflon membrane, with $2 \mathrm{~mm}$ pore size, is inserted to simulate the sieving effect of the pylorus.

Recently, Adouard et al. [204] adapted this model by adding a third compartment in order to simulate the stomach, duodenum and small intestine physiological conditions (i.e., separating the duodenum from the small intestine phase). The authors used this model to study the survivability of cheese-ripening microorganisms (i.e., six bacteria and three yeasts). Moreover, they also studied these microorganisms under different growth conditions (i.e., in cheese matrix and lab conditions). They observed that all yeasts (i.e., Geotrichum candidum, Kluyveromyces lactis and Debaryomyces hansenii) resisted to the in vitro digestion conditions, whereas one bacteria strain (i.e., Lactococcus lactis) did not survive to such conditions. On the other hand, bacteria stains (i.e., Brevibacterium aurantiacum and Arthrobacter arilaitensis) showed to be more sensitive to in vitro digestion when grown in the cheese matrix.

Chen et al. [205] developed a dynamic gastric simulation model (DGSM) which dynamically simulates the human gastric conditions during food digestion. This system is composed by a double-walled acrylic water insulated vessel and a probe attached to a texture analyzer. Recently, Tran Do et al. [206] adapted this model by making some modifications which include the addition of a continuous gastric secretion system, gastric emptying and a different probe apparatus - Fig. 6 .

The authors used this model to investigate the efficacy of selected supplemental digestive enzymes in order to improve food digestion. They concluded that supplementary enzymes improved food digestion during the in vitro gastric digestion.

The simulated human intestinal microbial ecosystem (SHIME ProDigest and Ghent University, Gent, Belgium) was developed by Molly et al. [207] and is composed by a five-chamber apparatus, simulating the human intestinal conditions (i.e., duodenum and jejunum, ileum, caecum and ascending colon, transverse colon and descending colon) coupled with pH probes and a pump system [207] - see Fig. 7. This model suffered some modification and actually the five vessels represent the human stomach, small intestine, ascending, transverse and descending colon, incorporating a microbial ecosystem in the large intestine vessels [208,209].

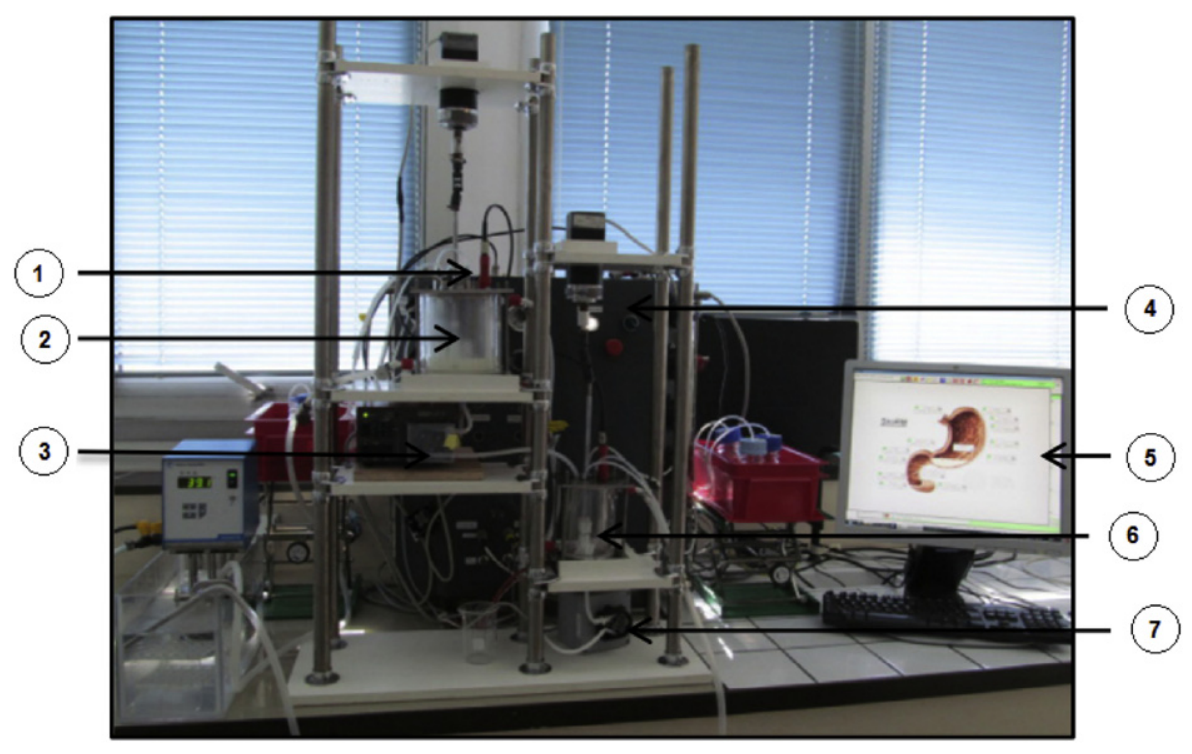

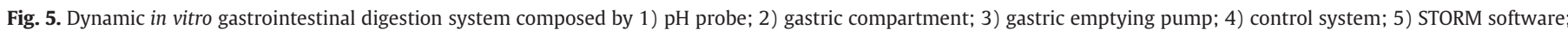
6) intestinal compartment and 7) intestinal emptying pump (Adapted from Ménard et al. [203]). 


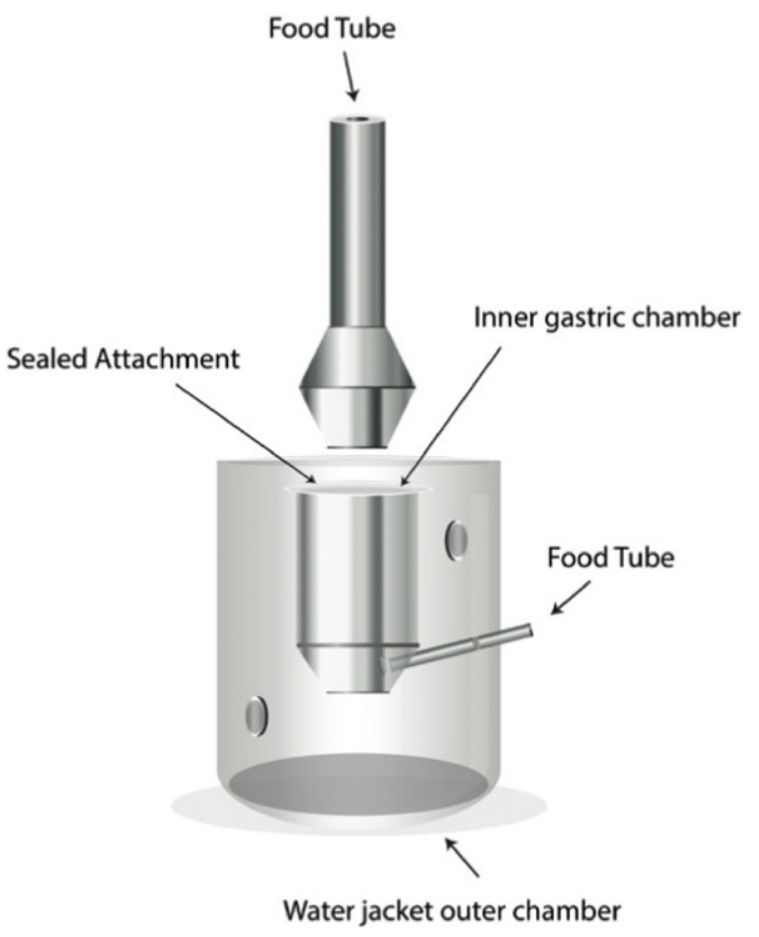

Fig. 6. Schematic representation of the dynamic gastric simulation model (Adapted from Tran Do et al. [206]).

Chaikham et al. [208] used this model to assess the survivability of microencapsulated probiotics (i.e., Lactobacillus acidophilus LA5 or Lactobacillus casei 01) suspended in pressurized longan juice. They observed that both encapsulated probiotics increased significantly the survival of bifidobacteria and decreased the pathogenic bacteria growth in the colon.

The dynamic in vitro digestion systems presented in this review have some similarities and disparities, however, all of them intended to study the digestion of food products/supplements under GI conditions. Table 3 compares the main conditions used in the dynamic digestion models previously presented.

Most of these systems are composed by a multi-compartment apparatus that simulate the different stages of the human GI tract, the transitions between the digestion phases (with the exception of the DGSM model), the gastric emptying, the $\mathrm{pH}$ transitions, the gastric and intestinal secretions and the peristaltic movements of the HDS. Although, these systems differ from each other regarding their complexity, some considerations have to be made regarding this subject. For instance, the SHIME is a complex in vitro digestion model due to the presence
Table 3

Comparison between different dynamic in vitro digestion models used to assess the behavior of bio-based micro- and nano-delivery systems developed for food applications.

\begin{tabular}{lllll}
\hline Characteristics & TIM-1 & DGID & DGSM & SHIME \\
\hline $\begin{array}{l}\text { Multi-chamber } \\
\text { (Number of chambers) }\end{array}$ & Yes $(4)$ & Yes $(3)$ & No & Yes $(5)$ \\
$\begin{array}{l}\text { Peristaltic Movements } \\
\text { pH transitions }\end{array}$ & Yes & Yes & Yes & No \\
Gastric emptying & Yes & Yes & No & Yes \\
Secretion addition & Yes & Yes & Yes & Yes \\
Cost & Yes & Yes & Yes & Yes \\
Complexity & $\$ \$ \$ \$ \$ \$$ & $\$ \$$ & $\$$ & $\$ \$ \$$ \\
Reference & +++ & ++ & + & +++ \\
\hline
\end{tabular}

Note: TIM-1: Dynamic in vitro digestion model developed by TNO Nutrition and Food Research; DGID: Dynamic gastrointestinal digester; IDM: In vitro digestion model; DGSM: Dynamic gastric simulation model; SHIME: Simulated human intestinal microbial ecosystem; \$: Low cost; $\$$ : Medium cost; $\$ \$$ : Expensive; $\$ \$ \$$ : Very expensive; +: Very simple; ++ : Simple; +++ : Complex; ++++ : Very complex.

of gut microbiota. However, gastric and small intestine secretions may lack in some important digestion conditions (e.g., enzymes and salts), since this system is focused on simulating the large intestine conditions. On the other hand, DGSM has a simple apparatus that intends to simulate the gastric conditions of the human body. However, this system presents a more complete enzymatic content and tries to simulate the stomach peristaltic movements. The TIM-1 system has an intermediate complex apparatus, when compared with the aforementioned systems, since it simulates the GI conditions of the HDS but it lacks in simulating the human large intestine. However, it is, in fact, a complete system because it mimics the gastric and small intestine secretions (i.e., enzymes and salts) and simulates the human GI peristaltic movements, present in vivo.

There are also other dynamic in vitro digestion models that exist based on the examples presented above. For instance, Pinheiro [158] developed a dynamic in vitro GI model, based on TIM-1, and several studies were conducted using this model. Bourbon et al. [210] assessed the ability of chitosan coating to interact and increase the stability of lactoferrin-glycomacropeptide nanohydrogels during gastric conditions. The authors showed that the presence of chitosan increased the nanohydrogels stability (i.e., reduced the rate of protein digestion). On the other hand, Pinheiro et al. [158] assessed the influence of different emulsifier types on the structural changes and bioavailability of curcumin nanoemulsions. The authors concluded that the emulsifier type (i.e., electrical charge) significantly influence the behavior of nanoemulsions regarding free fatty acids release and bioactive compound bioavailability.

Therefore, these in vitro digestion systems can be considered as a preliminary, but still crucial, step towards the study of functional food products digestion $[200,204,206,209]$.

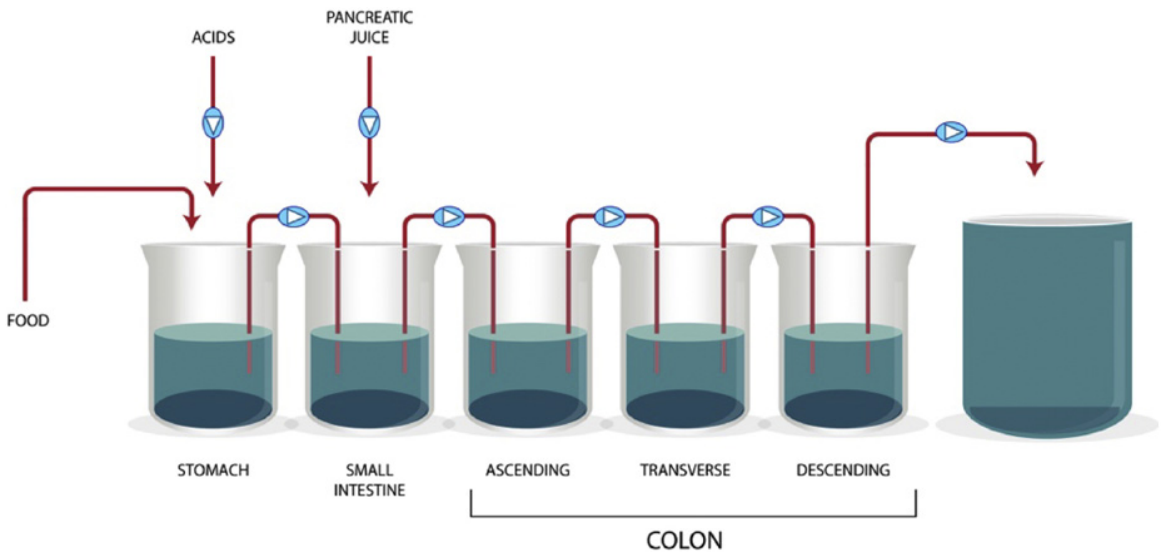

Fig. 7. Representative diagram of SHIME system (Adapted from Prodigest [256]). 


\subsection{Caco-2 cell models}

The use and optimization of cellular models with the purpose of evaluating the bioavailability and digestibility of bioactive compounds (e.g., flavonoids) has been increasing over the last years. These models try to mimic the conditions within the human small intestine allowing the determination of several conditions, namely, the bioaccumulation and toxicity level, the adhesion to or the absorption rate through intestinal epithelial cells [199,211,212].

Caco-2 cells are a human epithelial cell model, derived from colon carcinoma, with a heterogeneous cell population (i.e., they have different transport rates) that can rapidly differentiate into a monolayer of cells with the morphology and maturity of enterocytes. However, Caco-2 cells cannot produce a mucosal layer in order to simulate the intestinal mucosa. Therefore, Caco-2 cells can be co-cultured with HT29-MTX to replicate human intestinal mucosa. These co-cultured cell lines showed significant absorption disparities when compared with single Caco-2 cell lines [211,212]. A few studies are available addressing the effect of controlled delivery systems in the absorption and digestibility of bioactive compounds using Caco- 2 cell cultures.

Fernandez-Avila et al. [199] studied the effect of oil-in-water emulsions, stabilized with vegetable protein isolates (e.g., soy and pea protein isolates) on the protection and delivery of conjugated linoleic acid (CLA) using a Caco-2 cell culture. They observed that oil-in-water emulsions protected CLA during delivery, digestion and through transportation in the Caco-2 cell monolayer.

Grozdanovic et al. [213] investigated the impact of proteolytic activity of kiwifruit cysteine protease actinidin (Act $1 \mathrm{~d}$ ), in vitro and in vivo, by measuring permeability parameters in a Caco-2 cell model and in mice, respectively. The authors demonstrated that Act $1 \mathrm{~d}$ increased the permeability of the intestinal barrier by disrupting a human epithelial tight junction (occluding).

Despite the lack of ethical issues and the low cost of in vitro assays in comparison with in vivo counterparts, they do not meticulously mimic the HDS [214]. Therefore, in vivo studies need to be carried out in order to properly understand the behavior of micro- and nanosystems and of bioavailability of bioactive compounds under real digestive conditions.

\subsection{In vivo experiments}

In vivo assays can be performed in human or animal-nature organisms in order to understand the impact and behavior of micro- and nanosized delivery systems in the GI tract, as well as their digestibility. Some animal organisms are frequently used to perform in vivo experiments such as rodents, rabbits, pigs or calves. Pigs are the ones that more accurately mimic the HDS, since they are omnivorous colonic ferments, like humans $[215,216]$. Calves can also be used for milk digestion assays since they only use the abomasum (monogastric behavior) during their first two weeks of life. Rodents are usually employed to study the physiological conditions of the GI tract [215].

Chen et al. [217] studied the influence of liposomes coated with Ntrimethyl chitosan (TMC) in the absorption of harmine (HM) through in vivo assay, which it was performed on Sprague Dawley rats at a fasted state. The authors observed that such delivery systems prolonged the retention time of harmine, protecting it from enzymatic digestion and improving its transportation across the intestinal epithelial cells.

Jonathan et al. [216] studied the digestibility of alginate, and other dietary fibers, in pigs. They concluded that, in contrast to the solubility of alginate in water, its G-blocks precipitated in the colon.

O'Neill et al. [218] studied the effect of whey protein microbeads (dried at ambient conditions), to serve as carriers for riboflavin during in vitro and in vivo digestion. In vivo tests were performed on piglets and showed that dry whey protein microbeads were resistant to gastric digestion and retarded riboflavin release. The authors concluded that such structures can be used as delivery systems for riboflavin.
Both in vitro and in vivo assays are crucial for evaluating the behavior of controlled delivery systems during digestion, therefore comparisons and correlations between both methodologies are of ultimate importance and are for the first time carried out in this review paper.

\subsection{In vitro-in vivo correlations}

In vitro-in vivo correlations were categorized by the Food and Drug Administration (FDA) into five main levels - i.e., A, B, C, multiple level $C$ and $D$. Level A represents in vitro-in vivo point-to-point correlation; level B compares the mean of in vitro release time with the mean of in vivo residence or release time (i.e., statistical analysis); level C correlates a single release parameter (e.g., time required for $50 \%$ release) with a bioactive compound parameter (e.g., concentration). A multilevel $\mathrm{C}$ correlation compares multiple release time evaluations with multiple bioactive compounds parameters; while level $\mathrm{D}$ represents a rank order correlation. Usually, multiple correlation levels are used in an in vitro-in vivo correlations being level A a prerequisite to in vitro method validation [214].

Some studies were found in literature addressing how bio-based delivery systems would behave under digestion conditions using both in vitro and in vivo methodologies. Chen et al. [217] showed that nanosized liposomes coated with N-trimethyl chitosan (TMC) improved the bioavailability of harmine through in vitro (i.e., protection against Caco- 2 cells homogenates degradation) and in vivo (prolonged retention time in rats GI tract) methodologies. O'Neill et al. [218] demonstrated that whey protein microbeads retarded riboflavin release during both in vitro and in vivo GI digestion. Some differences were observed between the results obtained from both methodologies (i.e., in vitro and in vivo) regarding the riboflavin content released. Rawat et al. [214] studied the in vitro-in vivo correlations regarding the controlled release of commercial Risperdal in poly(lactide-co-glycolide) (PLGA) microspheres. Some variations were also observed in the release time of Risperdal between in vitro and in vivo experiments. The compound release was initially faster in the in vitro test, becoming slower after ca. 30 days, when compared with in vivo assays. The differences found among both methodologies may be due to some physiological dynamics that are typical of live organisms (i.e., in the in vivo GI tract), that are very difficult to mimic using in vitro models [214].

\section{Behavior of micro- and nanosystems in food models}

The incorporation of controlled delivery systems into food products has brought several advantages to the food industry. However, the behavior of such systems must be evaluated in food products prior to their commercialization, in order to understand the impact of food conditions on their properties and functionalities [174], structural stability $[219,220]$ and bioactive compounds bioavailability [86]. The addition of delivery systems to food products should not interfere with the sensory properties of the final product. At micro-, but particularly, at nanoscale delivery systems are imperceptible in the mouth and do not affect the sensory properties of the food product, thus increasing the public acceptance [174].

Therefore, some studies were performed regarding the incorporation of controlled delivery systems in food simulants (i.e., food model systems) and in food matrices (i.e., real food products), and will be discussed below.

\subsection{Food simulants}

According to the Commission Regulation (EU) No 10/2011 on plastic materials and articles intended to come into contact with food, several food simulants (showed in Table 4) were listed and regulated in order to study the impact of food environmental conditions on controlled release systems [221]. 
Table 4

List of available food simulants containing its composition and applications (Adapted from European Parliament and Council [221]).

\begin{tabular}{|c|c|c|}
\hline $\begin{array}{l}\text { Food } \\
\text { simulant }\end{array}$ & Composition & Application \\
\hline A & Ethanol 10\% (v/v) & Hydrophilic products \\
\hline B & Acetic acid 3\% (v/v) & $\begin{array}{l}\text { Hydrophilic and acidic products } \\
(\mathrm{pH}<4.5)\end{array}$ \\
\hline C & Ethanol 20\% (v/v) & $\begin{array}{l}\text { Hydrophilic and alcoholic } \\
\text { products ( }>20 \% \text { alcohol) }\end{array}$ \\
\hline D1 & Ethanol $50 \%(\mathrm{v} / \mathrm{v})$ & $\begin{array}{l}\text { Hydrophobic, alcoholic }(>20 \% \\
\text { alcohol) food products and } \\
\text { oil-in-water emulsions }\end{array}$ \\
\hline D2 & Vegetable oil & $\begin{array}{l}\text { Hydrophobic food products and } \\
\text { superficial fats }\end{array}$ \\
\hline $\mathrm{E}$ & $\begin{array}{l}\text { Poly(2,6-diphenyl-p-phenylene } \\
\text { oxide), particle size of } 60 \text { - } 80 \text { mesh, } \\
\text { pore size } 200 \mathrm{~nm}\end{array}$ & Dry food products \\
\hline
\end{tabular}

Most studies found in the literature use food simulants to study the migration of compounds, from food packaging to food products. Linsinger et al. [222], Su et al. [223] and Mackevica et al. [224] studied the migration of silver nanoparticles to food products using deionized water and $10 \%(\mathrm{v} / \mathrm{v})$ of ethanol; $3 \%(\mathrm{w} / \mathrm{v})$ of acetic acid and $50 \%(\mathrm{v} / \mathrm{v})$ of ethanol; and Milli-Q water, 3\% of acetic acid and 10\% of ethanol, respectively.

Only few studies are available on this subject regarding the use of controlled delivery systems. Madalena et al. [86] evaluated the stability of $\beta$-lactoglobulin encapsulated with riboflavin, when incorporated into a food simulant composed by Milli-Q water and 3\% of acetic acid, thus simulating a yoghurt product. These authors observed that $\beta$ lactoglobulin nanosystems remained structurally stable for 14 days of storage when compared with the control (i.e., $\beta$-lactoglobulin nanosystems in Milli-Q water), showing a complete release of riboflavin over 7 days of storage.

On the other hand, Liu et al. [163] encapsulated coenzyme Q10 in a nanostructured lipid carrier and added it to a food simulant composed by $15 \%$ of glucose, $0.1 \%$ of EDTANa $2,0.1 \%$ of benzoic acid and $83.9 \%$ of water $(\mathrm{w} / \mathrm{v})$, thus simulating a beverage. The authors showed that this nanostructured delivery system remained structurally stable during 3 months of storage, suggesting that it may be successfully applied in the food industry.

Food simulants represent, in fact, a good approach to evaluate the effect of food conditions on the stability of controlled delivery systems. However, assays in real food products are required because they provide more accurate results towards the influence of food product conditions on controlled delivery systems.

\subsection{Food matrices}

Food products can have a detrimental, neutral or protective effect over controlled delivery systems. Usually, food additives may include different types of sugars, salts, aromas, natural or artificial flavorings, among others. These additives can interact with delivery systems and decrease their bioavailability [225].

In the literature, some studies report the incorporation of controlled delivery systems in several food matrices, such as fruit juice [219,226], pastry dough [227], Cheddar cheese [228], yoghurt [229,230], chocolate [231] and bread [232].

Nualkaekul et al. [219] showed that encapsulation of Lactobacillus plantarum and Bifidobacterium longum in alginate and pectin microbeads successfully preserved their viability in pomegranate and cranberry juice during 6 weeks of storage; while Ying et al. [226] demonstrated that the viability of Lactobacillus rhamnosus was maintained when previously incorporated into spray dried microcapsules, and thus applied to apple juice. Both studies showed that microencapsulation of probiotics improved or maintained their viability in fruit juice.
Rivero et al. [227] assessed the controlled release of propionic acid, from chitosan films, into pastry dough, in order to improve its conservation properties. They concluded that chitosan is an effective carrier for propionic acid, promoting a controlled release of this antimicrobial compound, and thus successful presentation of pastry dough along time.

Amine et al. [228] studied the microencapsulation of Bifidobacterium longum in alginate beads to improve bacteria tolerance to freezing during Cheddar cheese production conditions and storage period. They concluded that alginate beads have a protective effect over bacteria, during 21 days of storage.

Gomes et al. [229] evaluated the incorporation of red bell pepper into $\beta$-cyclodextrin nanoparticles, and their stability when added into yoghurt, as well as the performance of different production techniques (i.e., magnetic stirring and ultrasonic homogenization), and the aspect of the resulting product. The authors concluded that the complex produced by ultrasonic homogenization showed less color changes in the yogurt, thus better preserving its properties during storage. Pando et al. [230] studied the ability of nanoniosome (composed by Span 60 or Maisine 35-1 as surfactants, and dodecanol as stabilizer) to encapsulate resveratrol and their stability in a yoghurt. They concluded that the complex formed by niosomes and resveratrol did not influence the product texture, showing that this delivery system is a suitable carrier for resveratrol for food applications.

Gültekin-Özgüven et al. [231] evaluate the encapsulation effect of nanoliposomes containing spray dried black mulberry extract and coated by chitosan in dark chocolate. The authors concluded that the chocolate properties were improved and fortified due to the incorporation of the aforementioned complex.

Rutz et al. [232] studied the encapsulation of palm oil and $\beta$-carotene into chitosan/sodium tripolyphosphate or chitosan/carboxymethyl cellulose microparticles, and evaluated their performance in food products (e.g., bread and yoghurt). They observed that chitosan/carboxymethyl cellulose delivery system improved carotenoid release during storage. From the tests described above, it is possible to see a positive effect of micro- and nanoencapsulation on bioactive compounds presentation and activity, thus improving its controlled release and performance when added to food products, without interfering negatively with the organoleptic properties of food products.

During this review, several micro- and nano delivery systems and bioactive compounds entrapped into them were evaluated in terms of their behavior and bioavailability, respectively, under digestion (through in vitro and in vivo experiments), and when incorporated in food simulants or real food systems. The information available regarding these subjects is, however, scarce and therefore more studies should be performed in order to better predict the behavior of delivery systems for their successfully commercialization in food products, in a near future.

\section{Safety and regulatory considerations}

Food safety focuses on the protection of food products against physical, chemical, biological and radiation contamination, during processing, storage and consumption. Nanotechnology is widely applied in the pharmaceutical and cosmetics fields while in the food industry is gaining popularity and a growing interest. However, the use of this technology may raise some security issues since it involves the deliberate manipulation, manufacture, processing or selection of materials, structures or systems at the nanometer scale, which may influence material properties (e.g., particle free movement through the human body due to their nanosized structure) $[113,186]$.

Particles at nanoscale display new properties and functionalities, which may improve the performance of traditional products. These innovative characteristics have an unpredictable impact in the human organism, animals or environment, due to potential toxic effects. Materials at this scale can penetrate and accumulate much deeper within the human body, breaching the cellular and sub-cellular boundaries, 
which may cause undesired and uncharacterized effects [233,234]. Moreover, long term effects regarding the application of nanotechnology to the food industry are still unknown [235].

Therefore, the use of nanotechnology for human consumption must be meticulously evaluated and regulated and consumer's acceptance studies should be performed in order to assess the consumer trends and to understand if what has been done is sufficient towards its acceptance and use in the food industry.

Regarding the regulatory measures for nanotechnology/ nanomaterials in food sector, a recent overview shows that still exists a lack of information exchange consistency among different countries, which may put in risk the human health and the environment, as well as restrict the commercialization of novel beneficial products at global level [236]. The European Union (EU) is, so far, the unique group of countries that have a clear regulatory definition of nanomaterials (and their intended use) in current food legislation. In countries outside the EU this regulation takes place in an implicit form that works only as a guide for the industry [236].

The European Commission (EC) published a definition of nanomaterial through regulation No 1169/2011 - “'engineered nanomaterial' means any intentionally produced material that has one or more dimensions of the order of $100 \mathrm{~nm}$ or less, or that is composed of discrete functional parts, either internally or at the surface, many of which have one or more dimensions in the order of $100 \mathrm{~nm}$ or less, including structures, agglomerates or aggregates, which may have a size above the order of $100 \mathrm{~nm}$ but retain properties that are characteristic of the nanoscale" [237]. This definition intends to inform the consumers and act as reference in different regulatory sectors. Regarding food contact materials and risk assessment, regulation (EU) no 10/2011 on plastic materials reports that nanoparticles may lead to different toxicological properties and thus should be evaluated on a case-bycase basis; it is mentioned that "authorizations which are based on the risk assessment of the conventional particle size of a substance do not cover engineered nanoparticles" [221]. Nanoparticles can only be used if explicitly authorized or named in Annex I of Regulation (EU) no 10/ 2011. In accordance with Annex I, only titanium nitride nanoparticles are reported and therefore, authorized until now. Furthermore, this regulation also states that nanoparticles should not be enclosed in the functional barrier concept, which basically allows the migration, below a given detection limit, of certain non-authorized substances present in multi-layer materials. Risk assessment of nanoparticles through on a case-by-case basis is also valid on active and intelligent materials, and articles intended to come into contact with food [238]; which means that a food additive authorization may be required, as well as for nanoparticles released intentionally from active food contact materials into the food matrix [236].

In terms of public acceptance or consumer attitudes, Handford et al. [235] performed a study involving 102 agri-food stakeholders (i.e., 14 interviews and 88 online questionnaires) to understand the current awareness regarding nanotechnology and its applications in the agrifood industry. The authors observed that the awareness regarding the application of nanotechnology to the agri-food industry is still on its preliminary stage. Although, some opportunities were identified, since the interviewed are more receptive when nanotechnology is used for human health benefit as "functional ingredients" or "more nutritional foods". Moreover, some risks were clearly identified regarding the "unknown effects to the human body and within the ecosystem" as well as "the lack of public knowledge regarding this subject, which may create doubt in the consumer". Therefore, toxicological studies must be made in order to reduce the dubious nature of this subject, regarding the use of nano delivery systems in food products [239].

Toxicological studies typically start with cytotoxicity assessments since one of the most important parameters to evaluate the toxicity of nanosystem materials is their biodegradability. This way, some studies were made regarding the cytotoxicity of controlled delivery nanosystems. Bruge et al. [239] studied the cytotoxicity of different nanostructured lipid carriers in human dermal fibroblasts. They concluded that all the formulations studied can be considered biocompatible materials. Although, they also observed that some formulations were susceptible to UVradiation, since they present an increase in the cytotoxicity level, under these conditions.

\section{Future trends}

The development of functional foods has increased over the past few years and has passed from a tendency to a reality in the food industry, as a response to a growing consumers' demand for more and more nutritional and healthy food products. In order to accomplish this evolutionary step, the information gathered by researchers and industrial food workers was essential. Thus, during this review, it was possible to detect some important trends regarding the application and production of controlled delivery micro- and nanosystems.

The development and application of micro- and nanoencapsulation techniques can be found during all steps of the food chain. The investment towards the development of novel approaches to scale up the application of micro- and nanoencapsulation to a large variety of processes and products is expected to increase in upcoming years.

To guarantee the desired functionality, the main trend is the reverse engineering approach. The reverse engineering approach is an ideal strategy for the development of micro- and nanosystems with specific characteristics, in order to be applied in food process and/or products. Regarding this methodology, the final product functionalities are previously determined. Subsequently, studies are conducted regarding the materials and methods that may be used to develop the desired delivery systems with the pre-required properties [4].

Innovations in the food industry also refer to new processing techniques. Electrospraying and electrospinning are emergent techniques for the production of fibers and/or capsules at the micro- and nanoscale. These versatile and low-cost methodologies can form structures with a high surface area-to-volume ratio. The principle of these techniques consists in applying an external electric field between two electrodes in the bio-based material solution, generating a repulsive force, opposite to the surface tension. While the droplet is exposed to an electric field, the solvent is evaporated and the fibers are formed [240,241].

The layer-by-layer technology is an emergent trend regarding the development of multilayer controlled delivery systems at micro- and nanoscale. This technique, based in the alternating deposition of polyelectrolytes with an opposite charge in a loaded structure, permit the design of delivery systems with greater performance in terms of controlled size, stability, composition and surface functionality [242,243].

\section{Acknowledgements}

Lívia de Souza Simões gratefully acknowledges her grant to CNPq (Conselho Nacional de Desenvolvimento Científico e Tecnológico, Brasil) from Brazil. Oscar L. Ramos and Ana C. Pinheiro gratefully acknowledge their Post-Doctoral grants (SFRH/BPD/80766/2011 and SFRH/BPD/101181/2014, respectively) to Portuguese Foundation for Science and Technology (FCT, Portugal). This study was supported by FCT under the scope of the strategic funding of UID/BIO/04469/2013 unit and COMPETE 2020 (POCI-01-0145-FEDER-006684) and BioTecNorte operation (NORTE-01-0145-FEDER-000004) funded by the European Regional Development Fund under the scope of Norte2020 - Programa Operacional Regional do Norte. This study was also supported by FCT under the scope of the Project RECI/BBB-EBI/0179/2012 (FCOMP-01-0124FEDER-027462).

\section{References}

[1] Benshitrit RC, Levi CS, Tal SL, Shimoni E, Lesmes U. Development of oral food-grade delivery systems: current knowledge and future challenges. Food Funct 2012;3:10 http://dx.doi.org/10.1039/c1fo10068h. 
[2] Balassa LL, Fanger GO, Wurzburg OB, Balassa LL, Fanger GO, Wurzburg OB, et al. Microencapsulation in the food industry - a practical implementation guide. First edit Elsevier; 2014. http://dx.doi.org/10.1080/10408397109527123.

[3] Durán N, Marcato PD. Nanobiotechnology perspectives. Role of nanotechnology in the food industry: a review. Int J Food Sci Technol 2013;48:1127-34. http://dx.doi. org/10.1111/ijfs.12027.

[4] Cerqueira MA, Pinheiro AC, Silva HD, Ramos PE, Azevedo MA, Flores-López ML, et al. Design of bio-nanosystems for oral delivery of functional compounds. Food Eng Rev 2014;6:1-19. http://dx.doi.org/10.1007/s12393-013-9074-3.

[5] Acosta E. Bioavailability of nanoparticles in nutrient and nutraceutical delivery. Curr Opin Colloid Interface Sci 2009;14:3-15. http://dx.doi.org/10.1016/j.cocis. 2008.01.002.

[6] Kwak H-S. Overview of nano- and microencapsulation for foods. In: Kwak H-S, editor. Nano-microencapsul. foods. First edit. John Wiley\& Sons; 2013. p. 1-14.

[7] Joye IJ, Davidov-Pardo G, McClements DJ. Nanotechnology for increased micronutrient bioavailability. Trends Food Sci Technol 2014;40:168-82. http://dx.doi.org/ 10.1016/j.tifs.2014.08.006.

[8] McClements DJ. Edible lipid nanoparticles: digestion, absorption, and potential toxicity. Prog Lipid Res 2013;52:409-23. http://dx.doi.org/10.1016/j.plipres.2013. 04.008.

[9] Garti N, McClements J. Encapsulation technologies and delivery systems for food ingredients and nutraceuticals. First edit. Woodhead Publishing Limited; 2012.

[10] Anandharamakrishnan C. Techniques for nanoencapsulation of food ingredients. New York: Springer; 2014. http://dx.doi.org/10.1007/978-1-4614-9387-7.

[11] Bagchi D, Bagchi M, Moriyama H, Shahidi F. Bio-nanotechnology - A Revolution in Food, Biomedical and Health Sciences. First. Wiley Blackwell; 2013.

[12] Ezhilarasi PN, Karthik P, Chhanwal N, Anandharamakrishnan C. Nanoencapsulation techniques for food bioactive components: a review. Food Bioprocess Technol 2013;6:628-47. http://dx.doi.org/10.1007/s11947-012-0944-0.

[13] Kwak H-S. Nano- and microencapsulation for foods. 1st ed. Wiley Blackwell; 2013

[14] Patel AR, Bhandari B. Nano- and microencapsulation of vitamins. In: Kwak H-S editor. Nano- and microencapsul. foods. First edit. JohnWiley\& Sons; 2012 p. 223-48. http://dx.doi.org/10.1002/9781118292327.fmatter.

[15] Tiwari R, Takhistov P. Nanotechnology - enabled delivery systems for food functionalization and fortification Introduction : functional foods. In: Padua GW, Wang Q editors. Nanotechnol. res. methods foods bioprod. First edit. John Wiley \& Sons; 2012. p. 55-101.

[16] Augustin MA, Hemar Y. Nano- and micro-structured assemblies for encapsulation of food ingredients. Chem Soc Rev 2009;38:902-12. http://dx.doi.org/10.1039/ b801739p.

[17] Vos P, Faas MM, Spasojevic M, Sikkema J. Encapsulation for preservation of functionality and targeted delivery of bioactive food components. Int Dairy J 2010;20: 292-302. http://dx.doi.org/10.1016/j.idairyj.2009.11.008.

[18] Belitz HD, Grosch W, Schieberle P. Food chemistry. 4th revise. Springer; 2009. http://dx.doi.org/10.1007/978-3-540-69934-7.

[19] Sirisha VL, Campus K. Polysaccharide nanoparticles: preparation and their potential application as drug delivery systems. Int J Res Appl Nat Soc Sci (IMPACT IJRANSS) 2015;3:69-94.

[20] Ramos OL, Pereira RN, Rodrigues R, Teixeira JA, Vicente AA, Xavier Malcata F. Physical effects upon whey protein aggregation for nano-coating production. Food Res Int 2014;66:344-55. http://dx.doi.org/10.1016/j.foodres.2014.09.036

[21] Livney YD. Milk proteins as vehicles for bioactives. Curr Opin Colloid Interface Sci 2010;15:73-83. http://dx.doi.org/10.1016/j.cocis.2009.11.002.

[22] Lee JW, Park JH, Robinson JR. Bioadhesive-based dosage forms: the next generation. J Pharm Sci 2000;89:850-66. http://dx.doi.org/10.1002/1520-6017(200007)89: 7<850::AID-JPS2>3.0.CO;2-G.

[23] Nitta SK, Numata K. Biopolymer-based nanoparticles for drug/gene delivery and tissue engineering. Int J Mol Sci 2013;14:1629-54. http://dx.doi.org/10.3390/ ijms14011629.

[24] Fathi M, Mozafari MR, Mohebbi M. Nanoencapsulation of food ingredients using carbohydrate based delivery systems. Trends Food Sci Technol 2014;23:13-27. http://dx.doi.org/10.1016/j.tifs.2011.08.003.

[25] Souza CJF, Garcia Rojas EE, Melo NR, Gaspar A, Lins JFC. Complex coacervates obtained from interaction egg yolk lipoprotein and polysaccharides. Food Hydrocoll 2013;30:375-81. http://dx.doi.org/10.1016/j.foodhyd.2012.06.012.

[26] Matalanis A, Jones OG, McClements DJ. Structured biopolymer-based delivery systems for encapsulation, protection, and release of lipophilic compounds. Food Hydrocoll 2011;25:1865-80. http://dx.doi.org/10.1016/j.foodhyd.2011.04. 014.

[27] Thakur VK, Thakur MK. Handbook of sustainable polymers. CRC Press Web; 2016.

[28] Li Y, McClements DJ. Controlling lipid digestion by encapsulation of proteinstabilized lipid droplets within alginate-chitosan complex coacervates. Food Hydrocoll 2011;25:1025-33. http://dx.doi.org/10.1016/j.foodhyd.2010.09.024.

[29] Birch NP, Schiffman JD. Characterization of self-assembled polyelectrolyte complex nanoparticles formed from chitosan and pectin. Langmuir 2014;30:3441-7. http:/ dx.doi.org/10.1021/la500491c.

[30] Damodaran S, Parkin KL, Fennema OR. Fennema's food chemistry. Fourth edi. CRC Press; 2008. http://dx.doi.org/10.1080/01932691.2011.584482.

[31] Ramos O, Pereira R, Martins A, Rodrigues R, Fuciños C, Teixeira JA, et al. Design of whey protein nanostructures for incorporation and release of nutraceutical compounds in food. Crit Rev Food Sci Nutr 2017;57:1377-93. http://dx.doi.org/10. 1080/10408398.2014.993749.

[32] Davidov-Pardo G, Joye IJ, McClements DJ. Food-grade protein-based nanoparticles and microparticles for bioactive delivery. In: Donev R, editor. Adv. Protein Chem Struct. Biol, First edit, vol. 98. Elsevier; 2015. p. 293-325. http://dx.doi.org/10. 1016/bs.apcsb.2014.11.004.
[33] Chen L, Remondetto GE, Subirade M. Food protein-based materials as nutraceutical delivery systems. Trends Food Sci Technol 2006;17:272-83. http://dx.doi.org/10. 1016/j.tifs.2005.12.011.

[34] Wan Z-L, Guo J, Yang X-Q. Plant protein-based delivery systems for bioactive ingredients in foods. Food Funct 2015;6:2876-89. http://dx.doi.org/10.1039/ C5FO00050E.

[35] Madureira AR, Pereira CI, Gomes AMP, Pintado ME, Xavier Malcata F. Bovine whey proteins - overview on their main biological properties. Food Res Int 2007;40: 1197-211. http://dx.doi.org/10.1016/j.foodres.2007.07.005.

[36] Ramos ÓL, Fernandes JC, Silva SI, Pintado ME, Malcata FX. Edible films and coatings from whey proteins: a review on formulation, and on mechanical and bioactive properties. Crit Rev Food Sci Nutr 2012;52:533-52. http://dx.doi.org/10.1080/ 10408398.2010.500528.

[37] Ramos OL, Pereira JO, Silva SI, Amorim MM, Fernandes JC, Lopes-da-Silva JA, et al. Effect of composition of commercial whey protein preparations upon gelation at various pH values. Food Res Int 2012;48:681-9. http://dx.doi.org/10.1016/j. foodres.2012.06.004.

[38] Balandrán-Quintana RR, Valdéz-Covarrubias MA, Mendoza-Wilson AM, SoteloMundo RR. $\alpha$-Lactalbumin hydrolysate spontaneously produces disk-shaped nanoparticles. Int Dairy J 2013;32:133-5. http://dx.doi.org/10.1016/j.idairyj.2013.05. 011.

[39] Monteiro AA, Monteiro MR, Pereira RN, Diniz R, Costa AR, Malcata FX, et al. Design of bio-based supramolecular structures through self-assembly of $\alpha$-lactalbumin and lysozyme. Food Hydrocoll 2016;58:60-74. http://dx.doi.org/10.1016/j. foodhyd.2016.02.009

[40] Silva HD, Cerqueira MÂ, Vicente AA. Nanoemulsions for food applications: development and characterization. Food Bioprocess Technol 2012;5:854-67. http://dx.doi. org/10.1007/s11947-011-0683-7.

[41] Aditya NP, Ko S. Solid lipid nanoparticles (SLNs): delivery vehicles for food bioactives. RSC Adv 2015;5:30902-11. http://dx.doi.org/10.1039/C4RA17127F.

[42] Tamjidi F, Shahedi M, Varshosaz J, Nasirpour A. Nanostructured lipid carriers (NLC): a potential delivery system for bioactive food molecules. Innovative Food Sci Emerg Technol 2013;19:29-43. http://dx.doi.org/10.1016/j.ifset.2013.03.002.

[43] Cruz Z, García-Estrada C, Olabarrieta I, Rainieri S. Lipid nanoparticles: delivery system for bioactive food compounds. In: Sagis LMC, editor. Microencapsul. Microsferas. First edit. Elsevier; 2015. p. 313-32. http://dx.doi.org/10.1007/ s13398-014-0173-7.2.

[44] Secolin VA, Souza CRF, Oliveira WP. Spray drying of lipid-based systems loaded with Camellia sinensis polyphenols. J Liposome Res 2016;2104:1-10. http://dx. doi.org/10.3109/08982104.2016.1140183.

[45] Ramadan MF. Antioxidant characteristics of phenolipids (quercetin-enriched lecithin) in lipid matrices. Ind Crop Prod 2012;36:363-9. http://dx.doi.org/10.1016/j. indcrop.2011.10.008.

[46] Tamjidi F, Nasirpour A, Shahedi M. Rheological characteristics of yogurt enriched with microencapsulated fish oil. J Agric Sci Technol 2014;16:1073-82. http://dx. doi.org/10.1177/1082013211428212.

[47] Fang Z, Bhandari B. Effect of spray drying and storage on the stability of bayberry polyphenols. Food Chem 2011;129:1139-47. http://dx.doi.org/10.1016/j. foodchem.2011.05.093.

[48] Arroyo-Maya IJ, McClements DJ. Biopolymer nanoparticles as potential delivery systems for anthocyanins: fabrication and properties. Food Res Int 2015;69:1-8. http://dx.doi.org/10.1016/j.foodres.2014.12.005

49] Duval S, Chung C, McClements DJ. Protein-polysaccharide hydrogel particles formed by biopolymer phase separation. Food Biophys 2015:1-8. http://dx.doi. org/10.1007/s11483-015-9396-1.

[50] Klein M, Aserin A, Ishai P Ben, Garti N. Interactions between whey protein isolate and gum Arabic. Colloids Surf B: Biointerfaces 2010;79:377-83. http://dx.doi.org/ 10.1016/j.colsurfb.2010.04.021.

[51] Luo Y, Zhang B, Whent M, Yu LL, Wang Q. Preparation and characterization of zein/ chitosan complex for encapsulation of alpha-tocopherol, and its in vitro controlled release study. Colloids Surf B: Biointerfaces 2011;85:145-52. http://dx.doi.org/10. 1016/j.colsurfb.2011.02.020

[52] Teng Z, Luo Y, Wang Q. Nanoparticles synthesized from soy protein: preparation, characterization, and application for nutraceutical encapsulation. J Agric Food Chem 2012;60:2712-20. http://dx.doi.org/10.1021/jf205238x.

[53] Ying DY, Phoon MC, Sanguansri L, Weerakkody R, Burgar I, Augustin MA. Microencapsulated Lactobacillus rhamnosus GG powders: relationship of powder physical properties to probiotic survival during storage. J Food Sci 2010;75:E588-95. http://dx.doi.org/10.1111/j.1750-3841.2010.01838.x.

[54] Mizrahy S, Peer D. Polysaccharides as building blocks for nanotherapeutics. Chem Soc Rev 2012;41:2623-40. http://dx.doi.org/10.1039/c1cs15239d.

[55] Hu B, Huang QR. Biopolymer based nano-delivery systems for enhancing bioavailability of nutraceuticals. Chin J Polym Sci 2013;31:1190-203. http://dx.doi.org/10. 1007/s10118-013-1331-7.

[56] Gao JY, Dubin PL, Muhoberac BB. Measurement of the binding of proteins to polyelectrolytes by frontal analysis continuous capillary electrophoresis. Anal Chem 1997;69:2945-51. http://dx.doi.org/10.1021/ac970026h.

[57] Ding X, Yao P. Soy protein/soy polysaccharide complex nanogels: folic acid loading protection, and controlled delivery. Langmuir 2013;29:8636-44. http://dx.doi.org/ 10.1021/la401664y.

[58] Dubey BN, Windhab EJ. Iron encapsulated microstructured emulsion-particle formation by prilling process and its release kinetics. J Food Eng 2013;115:198-206. http://dx.doi.org/10.1016/j.jfoodeng.2012.10.013.

[59] Gülseren I, Fang Y, Corredig M. Zinc incorporation capacity of whey protein nanoparticles prepared with desolvation with ethanol. Food Chem 2012;135:770-4. http://dx.doi.org/10.1016/j.foodchem.2012.04.146. 
[60] Dordevic V, Balanc B, Belscak-Cvitanovic A, Levic S, Trifkovic K, Kalusevic A, et al. Trends in encapsulation technologies for delivery of food bioactive compounds. Food Eng Rev 2014;7:452-90. http://dx.doi.org/10.1007/s12393-014-9106-7.

[61] Kumar V, Lemos M, Sharma M, Shriram V. Antioxidant and DNA damage protecting activities of Eulophia nuda. Free Radicals Antioxid 2013;3:55-60. http://dx.doi.org/ 10.1016/j.fra.2013.07.001.

[62] Quirós-Sauceda AE, Ayala-Zavala JF, Olivas GI, González-Aguilar GA. Edible coatings as encapsulating matrices for bioactive compounds: a review. J Food Sci Technol 2014;51:1674-85. http://dx.doi.org/10.1007/s13197-013-1246-X.

[63] Wadood A, Ghufran M, Jamal SB, Naeem M, Khan A, Ghaffar R. Phytochemical analysis of medicinal plants occurring in local area of Mardan. Biochem Anal Biochem 2013;2:2-5. http://dx.doi.org/10.4172/2161-1009.1000144.

[64] Armendáriz-Barragán B, Zafar N, Badri W, Galindo-Rodríguez SA, Kabbaj D, Fessi H, et al. Plant extracts: from encapsulation to application. Expert Opin Drug Deliv 2016;13:1165-75. http://dx.doi.org/10.1080/17425247.2016.1182487.

[65] Shome S, Talukdar A Das, Choudhury MD, Bhattacharya MK, Upadhyaya H. Curcumin as potential therapeutic natural product: a nanobiotechnological perspective. J Pharm Pharmacol 2016;68:1481-500. http://dx.doi.org/10.1111/jphp.12611.

[66] Summerlin N, Soo E, Thakur S, Qu Z, Jambhrunkar S, Popat A. Resveratrol nanoformulations: challenges and opportunities. Int J Pharm 2015;479:282-90. http://dx.doi.org/10.1016/j.ijpharm.2015.01.003.

[67] Souto EB, Severino P, Basso R, Santana MHA. Encapsulation of antioxidants in gastrointestinal-resistant nanoparticulate carriers. In: Armstrong D, Bharali DJ, editors. Oxidative stress nanotechnol. First edit. Humana Press; 2013. p. 37-46.

[68] Wang W, Sun C, Mao L, Ma P, Liu F, Yang J, et al. The biological activities, chemical stability, metabolism and delivery systems of quercetin: a review. Trends Food Sci Technol 2016;56:21-38. http://dx.doi.org/10.1016/j.tifs.2016.07.004.

[69] David S, Zagury Y, Livney YD. Soy $\beta$-conglycinin - curcumin nanocomplexes for enrichment of clear beverages. Food Biophys 2015;10:195-206. http://dx.doi.org/10. 1007/s11483-014-9386-8.

[70] Benzaria A, Maresca M, Taieb N, Dumay E. Interaction of curcumin with phosphocasein micelles processed or not by dynamic high-pressure. Food Chem 2013;138:2327-37. http://dx.doi.org/10.1016/j.foodchem.2012.12.017.

[71] Qv X, Zeng Z, Jiang J. Preparation of lutein microencapsulation by complex coacervation method and its physicochemical properties and stability. Food Hydrocoll 2011;25:1596-603. http://dx.doi.org/10.1016/j.foodhyd.2011.01.006.

[72] Mahdavi SA, Jafari SM, Ghorbani M, Assadpoor E. Spray-drying microencapsulation of anthocyanins by natural biopolymers: a review. Dry Technol 2014;32:509-18. http://dx.doi.org/10.1080/07373937.2013.839562.

[73] Betz M, Steiner B, Schantz M, Oidtmann J, Mäder K, Richling E, et al. Antioxidant capacity of bilberry extract microencapsulated in whey protein hydrogels. Food Res Int 2012;47:51-7. http://dx.doi.org/10.1016/j.foodres.2012.01.010.

[74] Tajkarimi MM, Ibrahim SA, Cliver DO. Antimicrobial herb and spice compounds in food. Food Control 2010;21:1199-218. http://dx.doi.org/10.1016/j.foodcont.2010. 02.003.

[75] Fu Y, Sarkar P, Bhunia AK, Yao Y. Delivery systems of antimicrobial compounds to food. Trends Food Sci Technol 2016;57:165-77. http://dx.doi.org/10.1016/j.tifs. 2016.09.013.

[76] Brandelli A, Lopes NA, Boelter JF. Food applications of nanostructured antimicrobials. In: Grumezescu AM, editor. Food Preserv. - Nanotechnol. Agri-Food Ind, First edit, vol. 6. Elsevier; 2017. p. 35-74.

[77] Donsì F, Annunziata M, Sessa M, Ferrari G. Nanoencapsulation of essential oils to enhance their antimicrobial activity in foods. LWT Food Sci Technol 2011;44: 1908-14. http://dx.doi.org/10.1016/j.lwt.2011.03.003.

[78] Liang R, Xu S, Shoemaker CF, Li Y, Zhong F, Huang Q. Physical and antimicrobial properties of peppermint oil nanoemulsions. J Agric Food Chem 2012;60: 7548-55. http://dx.doi.org/10.1021/jf301129k.

[79] Shah B, Davidson PM, Zhong Q. Nanodispersed eugenol has improved antimicrobial activity against Escherichia coli 0157:H7 and Listeria monocytogenes in bovine milk. Int J Food Microbiol 2013;161:53-9. http://dx.doi.org/10.1016/j.ijfoodmicro.2012. 11.020 .

[80] Ball GFM. Vitamins: their role in the human body. First edit. London, UK: Blackwell Publishing Ltd; 2004. http://dx.doi.org/10.1111/j.1365-2621.2005.01002.x.

[81] Combs Jr GF. The vitamins - fundamental aspects in nutrition and health. Third edit. Academic Press Ltd./Elsevier Science Ltd; 2013. http://dx.doi.org/10.1017/ CBO9781107415324.004

[82] Beztsinna N, Solé M, Taib N, Bestel I. Bioengineered riboflavin in nanotechnology. Biomaterials 2016;80:121-33. http://dx.doi.org/10.1016/j.biomaterials.2015.11. 050 .

[83] Katouzian I, Jafari SM. Nano-encapsulation as a promising approach for targeted delivery and controlled release of vitamins. Trends Food Sci Technol 2016;53: 34-48. http://dx.doi.org/10.1016/j.tifs.2016.05.002.

[84] Gironés-Vilaplana A, Villaño D, Marhuenda J, Moreno DA, García-Viguera C. Vitamins. In: Galanakis C, editor. Nutraceutical funct. food components. First edit. Elsevier; 2017. p. 159-201. http://dx.doi.org/10.1016/B978-0-12-805257-0. 00006-5.

[85] Pezeshki A, Ghanbarzadeh B, Mohammadi M, Fathollahi I, Hamishehkar H. Encapsulation of vitamin A palmitate in nanostructured lipid carrier (NLC)-effect of surfactant concentration on the formulation properties. Adv Pharm Bull 2014;4: 563-8. http://dx.doi.org/10.5681/apb.2014.083.

[86] Madalena DA, Ramos ÓL, Pereira RN, Bourbon AI, Pinheiro AC, Malcata FX, et al. In vitro digestion and stability assessment of $\beta$-lactoglobulin/riboflavin nanostructures. Food Hydrocoll 2016;58:89-97. http://dx.doi.org/10.1016/j.foodhyd.2016. 02.015 .

[87] Krasaekoopt W, Watcharapoka S. Effect of addition of inulin and galactooligosaccharide on the survival of microencapsulated probiotics in alginate beads coated with chitosan in simulated digestive system, yogurt and fruit juice. LWT Food Sci Technol 2014;57:761-6. http://dx.doi.org/10.1016/j.lwt.2014.01.037.

[88] Nedovic V, Kalusevic A, Manojlovic V, Levic S, Bugarski B. An overview of encapsulation technologies for food applications. Procedia Food Sci 2011;1:1816-20. http://dx.doi.org/10.1016/j.profoo.2011.09.266.

[89] Kailasapathy K. Microencapsulation for gastrointestinal delivery of probiotic bateria. In: Kwak H-S, editor. Nano- and microencapsulation for foods. First edit Wiley Blackwell; 2014. p. 167-97.

[90] Lahtinen S, Ouwehand AC, Salminen S, Von Wright A. Latic and bacteria - microbiological and functional aspects. Fourth edi. CRC Press; 2012.

[91] De Vrese M, Schrezenmeir J. Probiotics, prebiotics, and synbiotics. Adv Biochem Eng Biotechnol 2008;111:1-66. http://dx.doi.org/10.1007/10_2008_097.

[92] Murguía-Peniche T, Mihatsch WA, Zegarra J, Supapannachart S, Ding ZY, Neu J. Intestinal mucosal defense system, part 2. Probiotics Prebiotics J Pediatr 2013;162: S64-71. http://dx.doi.org/10.1016/j.jpeds.2012.11.055.

[93] Ubbink J, Krüger J. Physical approaches for the delivery of active ingredients in foods. Trends Food Sci Technol 2006;17:244-54. http://dx.doi.org/10.1016/j.tifs. 2006.01.007.

[94] Favaro-Trindade CS, Heinemann RJB, Pedroso DL. Developments in probiotic encapsulation. CAB Rev Perspect Agric Vetinary Sci Nutr Nat Resour 2011;6:1-8. http://dx.doi.org/10.1079/PAVSNNR20116004.

[95] Sarao LK, Arora M. Probiotics, prebiotics, and microencapsulation: a review. Crit Rev Food Sci Nutr 2017;57:344-71. http://dx.doi.org/10.1080/10408398.2014. 887055.

[96] Sarkar S. Approaches for enhancing the viability of probiotics: a review. Br Food J 2010;112:329-49. http://dx.doi.org/10.1108/00070701011034376.

[97] Priya AJ, Vijayalakshmi SP, Raichur AM. Enhanced survival of probiotic Lactobacillus acidophilus by encapsulation with nanostructured polyelectrolyte layers through layer-by-layer approach. J Agric Food Chem 2011;59:11838-45. http://dx.doi.org/ $10.1021 /$ jf203378s.

[98] Valcheva R, Dieleman LA. Prebiotics: definition and protective mechanisms. Best Pract Res Clin Gastroenterol 2016;30:27-37. http://dx.doi.org/10.1016/j.bpg.2016. 02.008 .

[99] Lomax AR, Calder PC. Prebiotics, immune function, infection and inflammation: a review of the evidence. Br J Nutr 2009;101:633-58. http://dx.doi.org/10.1017/ S000711450805561X

[100] Charalampopoulos D, Rastall RA. Prebiotics in foods. Curr Opin Biotechnol 2012;23: 187-91. http://dx.doi.org/10.1016/j.copbio.2011.12.028.

[101] Okuro PK, Thomazini M, Balieiro JCC, Liberal RDCO, Fávaro-Trindade CS. Coencapsulation of Lactobacillus acidophilus with inulin or polydextrose in solid lipid microparticles provides protection and improves stability. Food Res Int 2013;53:96-103. http://dx.doi.org/10.1016/j.foodres.2013.03.042.

[102] Rajam R, Anandharamakrishnan C. Microencapsulation of Lactobacillus plantarum (MTCC 5422) with fructooligosaccharide as wall material by spray drying. LWT Food Sci Technol 2015;60:773-80. http://dx.doi.org/10.1016/j. lwt.2014.09.062.

[103] Hosseini SF, Zandi M, Rezaei M, Farahmandghavi F. Two-step method for encapsulation of oregano essential oil in chitosan nanoparticles: preparation, characterization and in vitro release study. Carbohydr Polym 2013;95:50-6. http://dx.doi.org/ 10.1016/j.carbpol.2013.02.031.

[104] Fernandes RVDB, Borges SV, Botrel DA. Gum arabic/starch/maltodextrin/inulin as wall materials on the microencapsulation of rosemary essential oil. Carbohydr Polym 2014;101:524-32. http://dx.doi.org/10.1016/j.carbpol.2013.09.083.

[105] Koupantsis T, Pavlidou E, Paraskevopoulou A. Flavour encapsulation in milk proteins - CMC coacervate-type complexes. Food Hydrocoll 2014;37:134-42. http:// dx.doi.org/10.1016/j.foodhyd.2013.10.031.

[106] Jun-xia X, Hai-yan Y, Jian Y. Microencapsulation of sweet orange oil by complex coacervation with soybean protein isolate/gum Arabic. Food Chem 2011;125: 1267-72. http://dx.doi.org/10.1016/j.foodchem.2010.10.063.

[107] Jiang H, Zhang M, McKnight S, Adhikari B. Microencapsulation of $\alpha$-amylase by carrying out complex coacervation and drying in a single step using a novel threefluid nozzle spray drying. Dry Technol 2013;31:1901-10. http://dx.doi.org/10. 1080/07373937.2013.771365.

[108] McClements DJ. Food emulsions - principles, practices, and techniques. Third edit CRC Press; 2016.

[109] Hilty FM, Zimmermann MB. Nano-structured minerals and trace elements for food and nutrition applications. In: Kwak H-S, editor. Nano-microencapsul. foods. First edit. JohnWiley\& Sons; 2014. p. 199-222.

[110] Joye IJ, McClements DJ. Biopolymer-based nanoparticles and microparticles: Fabrication, characterization, and application. Curr Opin Colloid Interface Sci 2014;19: 417-27. http://dx.doi.org/10.1016/j.cocis.2014.07.002.

[111] Khadka P, Ro J, Kim H, Kim I, Kim JT, Kim H, et al. Pharmaceutical particle technologies: an approach to improve drug solubility, dissolution and bioavailability. Asian J Pharm Sci 2014;9:304-16. http://dx.doi.org/10.1016/j.ajps. 2014.05.005.

[112] Rai M, Caue R, Mattoso L, Duran N. Nanotechnologies in food and agriculture. First edit. Springer; 2015. http://dx.doi.org/10.1007/978-3-319-14024-7.

[113] Afroz QM, Swaminathan K, Karthikeyan P, Ahmed KP, Sudhir U, Kumar MU. Application of nanotechnology in food and dairy processing: an overview. Packag J Food Sci 2012;22:23-31.

[114] Kuan C-Y, Yee-Fung W, Yuen K-H, Liong M-T. Nanotech: propensity in foods and bioactives. Crit Rev Food Sci Nutr 2012;52:55-71. http://dx.doi.org/10.1080/ 10408398.2010.494259.

[115] Teleki A, Hitzfeld A, Eggersdorfer M. 100 years of vitamins: the science of formulation is the key to functionality. KONA Powder Part J 2012;30:144-63. http://dx.doi. org/10.14356/kona.2013015. 
[116] Norton JE, Gonzalez Espinosa Y, Watson RL, Spyropoulos F, Norton IT. Functiona food microstructures for macronutrient release and delivery. Food Funct 2015;6: 663-78. http://dx.doi.org/10.1039/c4fo00965g.

117] Đorđević V, Paraskevopoulou A, Mantzouridou F, Lalou S, Pantić M, Bugarski B, et al. Emerging and traditional technologies for safe, healthy and quality food. In: Nedović V, Raspor P, Lević J, Šaponjac V, Barbosa-Cánovas GV, editors. Emerg. tradit. technol. safe, heal. qual. food. First edit. Switzerland: Springer International Publishing; 2016. p. 329-82. http://dx.doi.org/10.1007/978-3-319-24040-4.

[118] Ray S, Raychaudhuri U, Chakraborty R. An overview of encapsulation of active compounds used in food products by drying technology. Food Biosci 2015;13:76-83. http://dx.doi.org/10.1016/j.fbio.2015.12.009.

[119] Ezhilarasi PN, Indrani D, Jena BS, Anandharamakrishnan C. Microencapsulation of Garcinia fruit extract by spray drying and its effect on bread quality. J Sci Food Agric 2014;94:1116-23. http://dx.doi.org/10.1002/jsfa.6378.

[120] Martin-Dejardin F, Ebel B, Lemetais G, Nguyen Thi Minh H, Gervais P, Cachon R, et al. A way to follow the viability of encapsulated Bifidobacterium bifidum subjected to a freeze-drying process in order to target the colon: interest of flow cytometry. Eur J Pharm Sci 2013;49:166-74. http://dx.doi.org/10.1016/j.ejps. 2013.02.015.

[121] Silva KA, Coelho MAZ, Calado VMA, Rocha-LeAão MHM. Olive oil and lemon salad dressing microencapsulated by freeze-drying. LWT Food Sci Technol 2013;50: 569-74. http://dx.doi.org/10.1016/j.lwt.2012.08.005.

[122] Spada JC, Marczak LDF, Tessaro IC, Noreña CPZ. Microencapsulation of $\beta$-carotene using native pinhão starch, modified pinhão starch and gelatin by freeze-drying. Int J Food Sci Technol 2012;47:186-94. http://dx.doi.org/10.1111/j.1365-2621. 2011.02825.x.

[123] Lee JS, Wong M. Nano- and microencapsulation of phytochemicals. In: Kwak H-S, editor. Nano-microencapsul. foods. First edit. John Wiley \& Sons; 2014. p. 119-65. http://dx.doi.org/10.1002/9781118292327.fmatter.

[124] Alvim ID, Souza FDS, Koury IP, Jurt T, Dantas BFH. Use of the spray chilling method to deliver hydrophobic components: physical characterization of microparticles. Ciênc E Tecnol Aliment 2013;33:34-9. http://dx.doi.org/10.1590/S010120612013000500006

[125] Silva DF, Favaro-Trindade CS, Rocha GA, Thomazini M. Microencapsulation of lycopene by gelatin-pectin complex coacervation. J Food Process Preserv 2012;36 185-90. http://dx.doi.org/10.1111/j.1745-4549.2011.00575.x.

[126] Jain A, Thakur D, Ghoshal G, Katare OP, Shivhare US. Microencapsulation by complex coacervation using whey protein isolates and gum acacia: an approach to preserve the functionality and controlled release of $\beta$-carotene. Food Bioprocess Technol 2015. http://dx.doi.org/10.1007/s11947-015-1521-0.

[127] Jain A, Thakur D, Ghoshal G, Katare OP, Shivhare US. Characterization of microcapsulated $\beta$-carotene formed by complex coacervation using casein and gum tragacanth. Int J Biol Macromol 2016;87:101-13. http://dx.doi.org/10.1016/ j.ijbiomac.2016.01.117

[128] Comunian TA, Thomazini M, Alves AJG, de Matos Junior FE, de Carvalho Balieiro JC Favaro-Trindade CS. Microencapsulation of ascorbic acid by complex coacervation: protection and controlled release. Food Res Int 2013;52:373-9. http://dx.doi.org/ 10.1016/j.foodres.2013.03.028.

[129] Ribeiro MCE, Chaves KS, Gebara C, Infante FNS, Grosso CRF, Gigante ML. Effect of microencapsulation of Lactobacillus acidophilus LA-5 on physicochemical, sensory and microbiological characteristics of stirred probiotic yoghurt. Food Res Int 2014;66:424-31. http://dx.doi.org/10.1016/j.foodres.2014.10.019.

[130] Yang Z, Peng Z, Li J, Li S, Kong L, Li P, et al. Development and evaluation of novel flavour microcapsules containing vanilla oil using complex coacervation approach. Food Chem 2014;145:272-7. http://dx.doi.org/10.1016/j.foodchem.2013.08.074.

[131] Dong Z, Ma Y, Hayat K, Jia C, Xia S, Zhang X. Morphology and release profile of microcapsules encapsulating peppermint oil by complex coacervation. J Food Eng 2011;104:455-60. http://dx.doi.org/10.1016/j.jfoodeng.2011.01.011.

[132] Teng Z, Luo Y, Wang Q. Carboxymethyl chitosan-soy protein complex nanoparticles for the encapsulation and controlled release of vitamin D3. Food Chem 2013;141: 524-32. http://dx.doi.org/10.1016/j.foodchem.2013.03.043.

[133] Shabanian J, Jafari R, Chaouki J. Fluidization of ultrafine powders. Int Rev Chem Eng 2012;4:16-50.

[134] Schell D, Beermann C. Fluidized bed microencapsulation of Lactobacillus reuter with sweet whey and shellac for improved acid resistance and in-vitro gastrointestinal survival. Food Res Int 2014;62:308-14. http://dx.doi.org/10.1016/j foodres.2014.03.016.

[135] Szulc K, Lenart A. Surface modification of dairy powders: effects of fluid-bed agglomeration and coating. Int Dairy J 2013;33:55-61. http://dx.doi.org/10.1016/j. idairyj.2013.05.021.

136] Coronel-Aguilera CP, San Martín-González MF. Encapsulation of spray dried bcarotene emulsion by fluidized bed coating technology. LWT Food Sci Technol 2015;62:187-93. http://dx.doi.org/10.1016/j.lwt.2014.12.036

[137] Anandharamakrishnan C, Ishwarya SP. Spray drying techniques for food ingredient encapsulation. First edit. Wiley Blackwell; 2015. http://dx.doi.org/10.1002/ 9781118863985.

[138] Wang W, Waterhouse GIN, Sun-Waterhouse D. Co-extrusion encapsulation of canola oil with alginate: effect of quercetin addition to oil core and pectin addition to alginate shell on oil stability. Food Res Int 2013;54:837-51. http://dx.doi.org/ 10.1016/j.foodres.2013.08.038.

[139] Shinde T, Sun-Waterhouse D, Brooks J. Co-extrusion encapsulation of probiotic Lactobacillus acidophilus alone or together with apple skin polyphenols: an aqueous and value-added delivery system using alginate. Food Bioprocess Technol 2014; 7:1581-96. http://dx.doi.org/10.1007/s11947-013-1129-1.

[140] Chew SC, Nyam KL. Microencapsulation of kenaf seed oil by co-extrusion technology. J Food Eng 2016;175:43-50. http://dx.doi.org/10.1016/j.jfoodeng.2015.12.002.
[141] McClements DJ. Nanoparticle- and microparticle-based delivery systems - encapsulation, protection and release of active compounds. First edit. CRC Press; 2015. http://dx.doi.org/10.1201/b17280.

[142] Santana RC, Perrechil FA, Cunha RL. High- and low-energy emulsifications for food applications: a focus on process parameters. Food Eng Rev 2013:5:107-22. http:// dx.doi.org/10.1007/s12393-013-9065-4.

[143] Lee LL, Niknafs N, Hancocks RD, Norton IT. Emulsification: mechanistic understanding. Trends Food Sci Technol 2013;31:72-8. http://dx.doi.org/10.1016/j.tifs.2012. 08.006 .

[144] Matalanis A, McClements DJ. Hydrogel microspheres for encapsulation of lipophilic components: optimization of fabrication \& performance. Food Hydrocoll 2013;31: 15-25. http://dx.doi.org/10.1016/j.foodhyd.2012.09.012.

[145] Mao L, Miao S. Structuring food emulsions to improve nutrient delivery during digestion. Food Eng Rev 2015;7:439-51. http://dx.doi.org/10.1007/s12393-015-9108-0.

[146] Wang S, Su R, Nie S, Sun M, Zhang J, Wu D, et al. Application of nanotechnology in improving bioavailability and bioactivity of diet-derived phytochemicals. J Nutr Biochem 2014;25:363-76. http://dx.doi.org/10.1016/j.jnutbio.2013.10.002.

[147] Vladisavljević GT, Kobayashi I, Nakajima M. Production of uniform droplets using membrane, microchannel and microfluidic emulsification devices. Microfluid Nanofluid 2012;13:151-78. http://dx.doi.org/10.1007/s10404-012-0948-0.

[148] Purwanti N, Ichikawa S, Neves MA, Uemura K, Nakajima M, Kobayashi I. $\beta$-Lactoglobulin as food grade surfactant for clove oil-in-water and limonene-in-water emulsion droplets produced by microchannel emulsification. Food Hydrocoll 2016;60:98-108. http://dx.doi.org/10.1016/j.foodhyd.2016.03.024.

[149] Akamatsu K, Kanasugi S, Nakao SI, Weitz DA. Membrane-integrated glass capillary device for preparing small-sized water-in-oil-in-water emulsion droplets. Langmuir 2015;31:7166-72. http://dx.doi.org/10.1021/acs.langmuir.5b01514.

[150] Vladisavljević GT, Wang B, Dragosavac MM, Holdich RG. Production of food-grade multiple emulsions with high encapsulation yield using oscillating membrane emulsification. Colloids Surf A Physicochem Eng Asp 2014;458:78-84. http://dx. doi.org/10.1016/j.colsurfa.2014.05.011.

[151] Nazir A, Schroën K, Boom R. Premix emulsification: a review. J Membr Sci 2010; 362:1-11. http://dx.doi.org/10.1016/j.memsci.2010.06.044.

[152] Nisisako T. Microstructured devices for preparing controlled multiple emulsions. Chem Eng Technol 2008;31:1091-8. http://dx.doi.org/10.1002/ceat.200800119.

[153] Neethirajan S, Kobayashi I, Nakajima M, Wu D, Nandagopal S, Lin F. Microfluidics for food, agriculture and biosystems industries. Lab Chip 2011;11:1574-86. http://dx.doi.org/10.1039/c0lc00230e

[154] Quintanilla-Carvajal MX, Camacho-Díaz BH, Meraz-Torres LS, Chanona-Pérez JJ, Alamilla-Beltrán L, Jimenéz-Aparicio A, et al. Nanoencapsulation: a new trend in food engineering processing. Food Eng Rev 2010;2:39-50. http://dx.doi.org/10. 1007/s12393-009-9012-6.

[155] Sekhon BS. Food-nanotechnology - an overview. J Nanotechnology, Sci Appl. Dove Press; 2010.

[156] Nidhi Rashid M, Kaur V, Hallan SS, Sharma S, Mishra N. Microparticles as controlled drug delivery carrier for the treatment of ulcerative colitis: a brief review. Saudi Pharm J 2016;24:458-72. http://dx.doi.org/10.1016/j.jsps.2014.10.001.

[157] Cui J, Van Koeverden MP, Müllner M, Kempe K, Caruso F. Emerging methods for the fabrication of polymer capsules. Adv Colloid Interf Sci 2014;207:14-31. http://dx. doi.org/10.1016/j.cis.2013.10.012.

[158] Pinheiro ACB. Development of nanostructures for application in food technology evaluation of their in vitro behavior. Minho University; 2013.

[159] Rubinstein M, Colby RH. Polymer physics. Oxford University Press; 2003. http://dx. doi.org/10.1017/CBO9780511975691.

[160] Ahmed EM. Hydrogel: preparation, characterization, and applications. J Adv Res 2013;6:105-21. http://dx.doi.org/10.1016/j.jare.2013.07.006.

[161] Singh NK, Lee DS. In situ gelling pH- and temperature-sensitive biodegradable block copolymer hydrogels for drug delivery. J Control Release 2014;193:214-27. http://dx.doi.org/10.1016/j.jconrel.2014.04.056.

[162] Das S, Chaudhury A. Recent advances in lipid nanoparticle formulations with solid matrix for oral drug delivery. AAPS PharmSciTech 2011;12:62-76. http://dx.doi. org/10.1208/s12249-010-9563-0.

[163] Liu GY, Wang JM, Xia Q. Application of nanostructured lipid carrier in food for the improved bioavailability. Eur Food Res Technol 2012;234:391-8. http://dx.doi.org/ 10.1007/s00217-011-1645-z.

[164] Tamjidi F, Shahedi M, Varshosaz J, Nasirpour A. Design and characterization of astaxanthin-loaded nanostructured lipid carriers. Innovative Food Sci Emerg Technol 2014;26:366-74. http://dx.doi.org/10.1016/j.ifset.2014.06.012.

[165] Zou L, Zheng B, Zhang R, Zhang Z, Liu W, Liu C, et al. Food-grade nanoparticles for encapsulation, protection and delivery of curcumin: comparison of lipid, protein, and phospholipid nanoparticles under simulated gastrointestinal conditions. RSC Adv 2016;6:3126-36. http://dx.doi.org/10.1039/C5RA22834D.

[166] Dolatabadi JEN, Hamishehkar H, Eskandani M, Valizadeh H. Formulation, characterization and cytotoxicity studies of alendronate sodium-loaded solid lipid nanoparticles. Colloids Surf B: Biointerfaces 2014;117:21-8. http://dx.doi.org/10.1016/j. colsurfb.2014.01.055.

[167] Joe MM, Chauhan PS, Bradeeba K, Shagol C, Sivakumaar PK, Sa T. Influence of sunflower oil based nanoemulsion (AUSN-4) on the shelf life and quality of IndoPacific king mackerel (Scomberomorus guttatus) steaks stored at $20{ }^{\circ} \mathrm{C}$. Food Control 2012;23:564-70. http://dx.doi.org/10.1016/j.foodcont.2011.08.032.

[168] Karthikeyan R, Amaechi BT, Rawls HR, Lee VA. Antimicrobial activity of nanoemulsion on cariogenic Streptococcus mutans. Arch Oral Biol 2011;56: 437-45. http://dx.doi.org/10.1016/j.archoralbio.2010.10.022.

[169] Machado AHE, Lundberg D, Ribeiro AJ, Veiga FJ, Lindman B, Miguel MG, et al. Preparation of calcium alginate nanoparticles using water-in-oil (W/O) nanoemulsions. Langmuir 2012;28:4131-41. http://dx.doi.org/10.1021/la204944j. 
[170] Pillai DS, Prabhasankar P, Jena BS, Anandharamakrishnan C. Microencapsulation of Garcinia cowa fruit extract and effect of its use on pasta process and quality. Int J Food Prop 2011;15:590-604. http://dx.doi.org/10.1080/10942912.2010.494756.

[171] Qian C, Decker EA, Xiao H, McClements DJ. Physical and chemical stability of bcarotene-enriched nanoemulsions: Influence of $\mathrm{pH}$, ionic strength, temperature, and emulsifier type. Food Chem 2012;132:1221-9. http://dx.doi.org/10.1016/j. foodchem.2011.11.091.

[172] Mao L, Roos YH, Biliaderis CG, Miao S. Food emulsions as delivery systems for flavor compounds - a review. Crit Rev Food Sci Nutr 2015;8398. http://dx.doi.org/10. 1080/10408398.2015.1098586.

[173] Sagalowicz L, Leser ME. Delivery systems for liquid food products. Curr Opin Colloid Interface Sci 2010;15:61-72. http://dx.doi.org/10.1016/j.cocis.2009.12.003.

[174] Livney YD. Nanostructured delivery systems in food: latest developments and potential future directions. Curr Opin Food Sci 2015;3:125-35. http://dx.doi.org/10. 1016/j.cofs.2015.06.010.

[175] Fathi M, Mozafari MR, Mohebbi M. Nanoencapsulation of food ingredients using lipid based delivery systems. Trends Food Sci Technol 2012;23:13-27. http://dx. doi.org/10.1016/j.tifs.2011.08.003.

[176] McClements DJ, Decker EA, Park Y, Weiss J. Structural design principles for delivery of bioactive components in nutraceuticals and functional foods. Crit Rev Food Sci Nutr 2009;49:577-606. http://dx.doi.org/10.1080/10408390902841529.

[177] Berton-Carabin CC, Coupland JN, Elias RJ. Effect of the lipophilicity of model ingredients on their location and reactivity in emulsions and solid lipid nanoparticles. Colloids Surf A Physicochem Eng Asp 2013;431:9-17. http://dx.doi.org/10.1016/j. colsurfa.2013.04.016.

[178] Gao S, McClements DJ. Formation and stability of solid lipid nanoparticles fabricated using phase inversion temperature method. Colloids Surf A Physicochem Eng Asp 2016;499:79-87. http://dx.doi.org/10.1016/j.colsurfa.2016.03.065.

[179] Helgason T, Salminen H, Kristbergsson K, McClements DJ, Weiss J. Formation of transparent solid lipid nanoparticles by microfluidization: Influence of lipid physical state on appearance. J Colloid Interface Sci 2015;448:114-22. http://dx.doi.org/ 10.1016/j.jcis.2015.02.010.

[180] Brandelli A. Nanobiotechnology strategies for delivery of antimicrobials in agriculture and food. In: Rai M, Ribeiro C, Mattoso L, Duran N, editors. Nanotechnologies food agric. Switzerland: Springer International Publishing; 2015. p. 119-39. http://dx.doi.org/10.1007/978-3-319-14024-7.

[181] Aditya NP, Macedo AS, Doktorovova S, Souto EB, Kim S, Chang PS, et al. Development and evaluation of lipid nanocarriers for quercetin delivery: a comparative study of solid lipid nanoparticles (SLN), nanostructured lipid carriers (NLC), and lipid nanoemulsions (LNE). LWT Food Sci Technol 2014;59:115-21. http://dx.doi. org/10.1016/j.lwt.2014.04.058.

[182] Gutiérrez FJ, Albillos SM, Casas-Sanz E, Cruz Z, García-Estrada C, García-Guerra A, et al. Methods for the nanoencapsulation of $\beta$-carotene in the food sector. Trends Food Sci Technol 2013;32:73-83. http://dx.doi.org/10.1016/j.tifs.2013.05.007.

[183] Dima S, Dima C, Iordachescu G. Encapsulation of functional lipophilic food and drug biocomponents. Food Eng Rev 2015;7:417-38. http://dx.doi.org/10.1007/s12393015-9115-1.

[184] Pool H, Mendoza S, Xiao H, McClements DJ. Encapsulation and release of hydrophobic bioactive components in nanoemulsion-based delivery systems: impact of physical form on quercetin bioaccessibility. Food Funct 2013;4:162-74. http://dx. doi.org/10.1039/C2FO30042G.

[185] McClements DJ. Encapsulation, protection, and release of hydrophilic active components: potential and limitations of colloidal delivery systems. Adv Colloid Interf Sci 2015;219:27-53. http://dx.doi.org/10.1016/j.cis.2015.02.002.

[186] Martins JT, Ramos OL, Pinheiro AC, Bourbon AI, Silva HD, Rivera MC, et al. Edible bio-based nanostructures: delivery, absorption and potential toxicity. Food Eng Rev 2015;7:491-513. http://dx.doi.org/10.1007/s12393-015-9116-0.

[187] Singh H, Sarkar A. Behaviour of protein-stabilised emulsions under various physiological conditions. Adv Colloid Interf Sci 2011;165:47-57. http://dx.doi.org/10. 1016/j.cis.2011.02.001

[188] Guerra A, Etienne-Mesmin L, Livrelli V, Denis S, Blanquet-Diot S, Alric M. Relevance and challenges in modeling human gastric and small intestinal digestion. Trends Biotechnol 2012;30:591-600. http://dx.doi.org/10.1016/j.tibtech.2012.08.001.

[189] Guergoletto KB, Costabile A, Flores G, Garcia S, Gibson GR. In vitro fermentation of juçara pulp (Euterpe edulis) by human colonic microbiota. Food Chem 2016;196: 251-8. http://dx.doi.org/10.1016/j.foodchem.2015.09.048.

[190] Alminger M, Aura AM, Bohn T, Dufour C, El SN, Gomes A, et al. In vitro models for studying secondary plant metabolite digestion and bioaccessibility. Compr Rev Food Sci Food Saf 2014;13:413-36. http://dx.doi.org/10.1111/1541-4337.12081.

[191] Li J, Ye A, Lee SJ, Singh H. Physicochemical behaviour of WPI-stabilized emulsions in in vitro gastric and intestinal conditions. Colloids Surf B: Biointerfaces 2013;111: 80-7. http://dx.doi.org/10.1016/j.colsurfb.2013.05.034.

[192] Miller D, Schricker B, Rasmussen R, Van Campen D. An in vitro method for estimation of iron availability from meals. Am J Clin Nutr 1981;34:2248-56.

[193] Minekus M, Alminger M, Alvito P, Ballance S, Bohn T, Bourlieu C, et al. A standardised static in vitro digestion method suitable for food - an international consensus. Food Funct 2014;5:1113-24. http://dx.doi.org/10.1039/c3fo60702j.

[194] Bokkhim H, Bansal N, Grøndahl L, Bhandari B. In-vitro digestion of different forms of bovine lactoferrin encapsulated in alginate micro-gel particles. Food Hydrocoll 2015;52:231-42. http://dx.doi.org/10.1016/j.foodhyd.2015.07.007.

[195] Madureira AR, Pereira A, Pintado M. Chitosan nanoparticles loaded with 2,5dihydroxybenzoic acid and protocatechuic acid: properties and digestion. J Food Eng 2016;174:8-14. http://dx.doi.org/10.1016/j.jfoodeng.2015.11.007.

[196] Peram MR, Loveday SM, Ye A, Singh H. In vitro gastric digestion of heat-induced aggregates of $\beta$-lactoglobulin. J Dairy Sci 2013;96:63-74. http://dx.doi.org/10.3168/ jds.2012-5896.
[197] Akbari A, Wu J. Cruciferin nanoparticles: preparation, characterization and their potential application in delivery of bioactive compounds. Food Hydrocoll 2016: 54:107-18. http://dx.doi.org/10.1016/j.foodhyd.2015.09.017.

[198] Zhang R, Zhang Z, Zou L, Xiao H, Zhang G, Decker EA, et al. Enhancement of carotenoid bioaccessibility from carrots using excipient emulsions: influence of particle size of digestible lipid droplets. Food Funct 2016;7:93-103. http://dx.doi.org/10 1039/C5FO01172H.

[199] Fernandez-Avila C, Arranz E, Guri A, Trujillo AJ, Corredig M. Vegetable protein isolatestabilized emulsions for enhanced delivery of conjugated linoleic acid in Caco-2 cells Food Hydrocoll 2016;55:144-54. http://dx.doi.org/10.1016/j.foodhyd.2015.10.015.

[200] Villemejane C, Denis S, Marsset-Baglieri A, Alric M, Aymard P, Michon C. In vitro digestion of short-dough biscuits enriched in proteins and/or fibres using a multicompartmental and dynamic system (2): protein and starch hydrolyses. Food Chem 2016;190:164-72. http://dx.doi.org/10.1016/j.foodchem.2015.05.050.

[201] Verwei M, Freidig AP, Havenaar R, Groten JP. Predicted serum folate concentrations based on in vitro studies and kinetic modeling are consistent with measured folate concentrations in humans. J Nutr 2006;136:3074-8.

[202] Fondaco D, AlHasawi F, Lan Y, Ben-Elazar S, Connolly K, Rogers MA. Biophysical aspects of lipid digestion in human breast milk and Similac ${ }^{\mathrm{TM}}$ infant formulas. Food Biophys 2015;10:282-91. http://dx.doi.org/10.1007/s11483-014-9388-6.

[203] Ménard O, Cattenoz T, Guillemin H, Souchon I, Deglaire A, Dupont D, et al. Validation of a new in vitro dynamic system to simulate infant digestion. Food Chem 2014;145:1039-45. http://dx.doi.org/10.1016/j.foodchem.2013.09.036.

[204] Adouard N, Magne L, Cattenoz T, Guillemin H, Foligné B, Picque D, et al. Survival of cheese-ripening microorganisms in a dynamic simulator of the gastrointestinal tract. Food Microbiol 2016;53:30-40. http://dx.doi.org/10.1016/j.fm.2015.03.002.

[205] Chen J, Gaikwad V, Holmes M, Murray B, Povey M, Wang Y, et al. Development of a simple model device for in vitro gastric digestion investigation. Food Funct 2011;2: 174-82. http://dx.doi.org/10.1039/c0fo00159g.

[206] Tran Do DH, Kong F, Penet C, Winetzky D, Gregory K. Using a dynamic stomach model to study efficacy of supplemental enzymes during simulated digestion. LWT Food Sci Technol 2016;65:580-8. http://dx.doi.org/10.1016/j.lwt.2015.08.054.

[207] Molly K, Vande Woestyne M, Verstraete W. Development of a 5-step multichamber reactor as a simulation of the human intestinal microbial ecosystem. Appl Microbiol Biotechnol 1993;39:254-8. http://dx.doi.org/10.1007/BF00228615.

[208] Chaikham P, Apichartsrangkoon A, Jirarattanarangsri W, Van de Wiele T. Influence of encapsulated probiotics combined with pressurized longan juice on colon microflora and their metabolic activities on the exposure to simulated dynamic gastrointestinal tract. Food Res Int 2012;49:133-42. http://dx.doi.org/10.1016/j.foodres. 2012.07.033.

[209] Daguet D, Pinheiro I, Verhelst A, Possemiers S, Marzorati M. Arabinogalactan and fructooligosaccharides improve the gut barrier function in distinct areas of the colon in the simulator of the human intestinal microbial ecosystem. J Funct Foods 2016;20:369-79. http://dx.doi.org/10.1016/j.jff.2015.11.005.

[210] Bourbon AI, Pinheiro AC, Cerqueira MA, Vicente AA. Influence of chitosan coating on protein-based nanohydrogels properties and in vitro gastric digestibility. Food Hydrocoll 2016;60:109-18. http://dx.doi.org/10.1016/j.foodhyd.2016.03.002.

[211] Kamiloglu S, Capanoglu E, Grootaert C, van Camp J. Anthocyanin absorption and metabolism by human intestinal Caco-2 cells - a review. Int J Mol Sci 2015;16: 21555-74. http://dx.doi.org/10.3390/ijms160921555.

[212] Gonzales GB, Van Camp J, Vissenaekens H, Raes K, Smagghe G, Grootaert C. Review on the use of cell cultures to study metabolism, transport, and accumulation of flavonoids: from mono-cultures to co-culture systems. Compr Rev Food Sci Food Saf 2015;14:741-54. http://dx.doi.org/10.1111/1541-4337.12158.

[213] Grozdanovic MM, Čavić M, Nešić A, Andjelković U, Akbari P, Smit JJ, et al. Kiwifruit cysteine protease actinidin compromises the intestinal barrier by disrupting tight junctions. Biochim Biophys Acta 1860;2016:516-26. http://dx.doi.org/10.1016/j. bbagen.2015.12.005.

[214] Rawat A, Bhardwaj U, Burgess DJ. Comparison of in vitro-in vivo release of Risperdal ${ }^{\circledR}$ Consta ${ }^{\circledR}$ microspheres. Int J Pharm 2012;434:115-21. http://dx.doi. org/10.1016/j.ijpharm.2012.05.006.

[215] Boutrou R, Henry G, Sanchez-Rivera L. On the trail of milk bioactive peptides in human and animal intestinal tracts during digestion: a review. Dairy Sci Technol 2015;95:815-29. http://dx.doi.org/10.1007/s13594-015-0210-0.

[216] Jonathan M, Souza Da Silva C, Bosch G, Schols H, Gruppen H. In vivo degradation of alginate in the presence and in the absence of resistant starch. Food Chem 2015; 172:117-20. http://dx.doi.org/10.1016/j.foodchem.2014.09.046.

[217] Chen W, Yuan Z-Q, Liu Y, Zhang C, Li J, Zhu W, et al. Liposomes coated with $\mathrm{N}$ trimethyl chitosan to improve the absorption of harmine in vivo and in vitro. Int J Nanomedicine 2016;11:325-36.

218] O'Neill GJ, Jacquier JC, Mukhopadhya A, Egan T, O'Sullivan M, Sweeney T, et al. In vitro and in vivo evaluation of whey protein hydrogels for oral delivery of riboflavin. J Funct Foods 2015;19:512-21. http://dx.doi.org/10.1016/j.jff.2015.09.043.

[219] Nualkaekul S, Cook MT, Khutoryanskiy VV, Charalampopoulos D. Influence of encapsulation and coating materials on the survival of Lactobacillus plantarum and Bifidobacterium longum in fruit juices. Food Res Int 2013;53:304-11. http://dx.doi. org/10.1016/j.foodres.2013.04.019.

[220] Wilde SC, Keppler JK, Palani K, Schwarz K. $\beta$-Lactoglobulin as nanotransporter for allicin: sensory properties and applicability in food. Food Chem 2016;199: 667-74. http://dx.doi.org/10.1016/j.foodchem.2015.12.055.

[221] European Parliament and Council. Regulation (EU) No 10/2011 of the European Parliament and of the Council of 14 January 2011 on on plastic materials and articles intended to come into contact with food. Off J Eur Union 2011:1-89.

[222] Linsinger TPJ, Peters R, Weigel S. International interlaboratory study for sizing and quantification of $\mathrm{Ag}$ nanoparticles in food simulants by single-particle ICPMS. Ana Bioanal Chem 2013;406:3835-43. http://dx.doi.org/10.1007/s00216-013-7559-9. 
223] Su Q-Z, Lin Q-B, Chen C-F, Wu Y-M, Wu L-B, Chen X-Q, et al. Effect of antioxidants and light stabilisers on silver migration from nanosilver-polyethylene composite packaging films into food simulants. Food Addit Contam Part A 2015;32:1561-6. http://dx.doi.org/10.1080/19440049.2015.1075258.

[224] Mackevica A, Olsson ME, Hansen SF. Silver nanoparticle release from commercially available plastic food containers into food simulants. J Nanopart Res 2016;18:1-11. http://dx.doi.org/10.1007/s11051-015-3313-x.

225] Tripathi MK, Giri SK. Probiotic functional foods: survival of probiotics during processing and storage. J Funct Foods 2014;9:225-41. http://dx.doi.org/10.1016/j.jff. 2014.04.030.

[226] Ying D, Schwander S, Weerakkody R, Sanguansri L, Gantenbein-Demarchi C, Augustin MA. Microencapsulated Lactobacillus rhamnosus GG in whey protein and resistant starch matrices: probiotic survival in fruit juice. J Funct Foods 2013; 5:98-105. http://dx.doi.org/10.1016/j.jff.2012.08.009.

[227] Rivero S, Giannuzzi L García MA, Pinotti A Controlled delivery of propionic acid from chitosan films for pastry dough conservation. J Food Eng 2013;116:524-31. http://dx.doi.org/10.1016/j.jfoodeng.2012.12.025

228] Amine KM, Champagne CP, Raymond Y, St-Gelais D, Britten M, Fustier P, et al. Survival of microencapsulated Bifidobacterium longum in Cheddar cheese during production and storage. Food Control 2013;37:193-9. http://dx.doi.org/10.1016/j. foodcont.2013.09.030.

[229] Gomes LMM, Petito N, Costa VG, Falcão DQ De Lima Araújo KG. Inclusion complexes of red bell pepper pigments with $\beta$-cyclodextrin: preparation, characterisation and application as natural colorant in yogurt. Food Chem 2014;148:428-36. http://dx.doi.org/10.1016/j.foodchem.2012.09.065.

[230] Pando D, Beltrán M, Gerone I, Matos M, Pazos C. Resveratrol entrapped niosomes as yoghurt additive. Food Chem 2015;170:281-7. http://dx.doi.org/10.1016/j. foodchem.2014.08.082.

[231] Gültekin-Özgüven M, Karadağ A, Duman S, Özkal B, Özcelik B. Fortification of dark chocolate with spray dried black mulberry (Morus nigra) waste extract encapsulat ed in chitosan-coated liposomes and bioaccessability studies. Food Chem 2016; 201:205-12. http://dx.doi.org/10.1016/j.foodchem.2016.01.091.

[232] Rutz JK, Borges CD, Zambiazi RC, da R Cleonice G, da S Médelin M. Elaboration of microparticles of carotenoids from natural and synthetic sources for applications in food. Food Chem 2016;202:324-33. http://dx.doi.org/10.1016/j.foodchem. 2016.01.140.

[233] Coles D, Frewer LJ. Nanotechnology applied to European food production - a review of ethical and regulatory issues. Trends Food Sci Technol 2013;34:32-43. http://dx. doi.org/10.1016/j.tifs.2013.08.006.

[234] Bumbudsanpharoke N, Ko S. Nano-food packaging: an overview of market, migration research, and safety regulations. J Food Sci 2015;80:R910-23. http://dx.doi. org/10.1111/1750-3841.12861.

[235] Handford CE, Dean M, Spence M, Henchion M, Elliott CT, Campbell K. Awareness and attitudes towards the emerging use of nanotechnology in the agri-food sector. Food Control 2015;57:24-34. http://dx.doi.org/10.1016/j.foodcont.2015.03.033.

[236] Amenta V, Aschberger K, Arena M, Bouwmeester H, Botelho Moniz F, Brandhoff P, et al. Regulatory aspects of nanotechnology in the agri/feed/food sector in EU and non-EU countries. Regul Toxicol Pharmacol 2015;73:463-76. http://dx.doi.org/10. 1016/j.yrtph.2015.06.016.

237] European Parliament and Council. Regulation (EU) no 1169/2011 of the European Parliament and of the Council of 25 October 2011 on the provision of food information to consumers. Off J Eur Union 2011;2011:18-63.

[238] EUROPEAN COMMISSION. Commission Regulation (EC) no 450/2009 of 29 May 2009 on active and intelligent materials and articles intended to come into contact with food. Off J Eur Union 2009:3-11.

[239] Bruge F, Damiani E, Marcheggiani F, Offerta A, Puglia C, Tiano L. A comparative study on the possible cytotoxic effects of different nanostructured lipid carrie (NLC) compositions in human dermal fibroblasts. Int J Pharm 2015;495:879-85. http://dx.doi.org/10.1016/j.ijpharm.2015.09.033.
[240] Tavares GM, Croguennec T, Carvalho AF, Bouhallab S. Milk proteins as encapsulation devices and delivery vehicles: applications and trends. Trends Food Sci Technol 2014;37:5-20. http://dx.doi.org/10.1016/j.tifs.2014.02.008.

[241] El-Salam MHA, El-Shibiny S. Preparation and properties of milk proteins-based encapsulated probiotics: a review. Dairy Sci Technol 2015;95:1-20. http://dx.doi.org/ 10.1007/s13594-015-0223-8.

[242] Pinheiro AC, Bourbon AI, Cerqueira MA, Maricato É, Nunes C, Coimbra MA, et al. Chitosan/fucoidan multilayer nanocapsules as a vehicle for controlled release of bioactive compounds. Carbohydr Polym 2015;115:1-9. http://dx.doi.org/10.1016/ j.carbpol.2014.07.016

[243] Rivera MC, Pinheiro AC, Bourbon AI, Cerqueira MA, Vicente AA. Hollow chitosan/alginate nanocapsules for bioactive compound delivery. Int J Biol Macromol 2015;79: 95-102. http://dx.doi.org/10.1016/j.jibiomac.2015.03.003.

[244] Rocha GA, Fávaro-Trindade CS, Grosso CRF. Microencapsulation of lycopene by spray drying: characterization, stability and application of microcapsules. Food Bioprod Process 2012;90:37-42. http://dx.doi.org/10.1016/j.fbp.2011.01.001.

[245] Bustos-Garza C, Yáñez-Fernández J, Barragán-Huerta BE. Thermal and pH stability of spray-dried encapsulated astaxanthin oleoresin from Haematococcus pluvialis using several encapsulation wall materials. Food Res Int 2013;54:641-9. http:// dx.doi.org/10.1016/j.foodres.2013.07.061

[246] Hedayati R, Jahanshahi M, Attar H. Fabrication and characterization of albuminacacia nanoparticles based on complex coacervation as potent nanocarrier. J Chem Technol Biotechnol 2012;87:1401-8. http://dx.doi.org/10.1002/jctb.3758.

[247] Akhavan Mahdavi S, Jafari SM, Assadpoor E, Dehnad D. Microencapsulation optimization of natural anthocyanins with maltodextrin, gum Arabic and gelatin. Int J Biol Macromol 2016;85:379-85. http://dx.doi.org/10.1016/j.ijbiomac.2016.01.011.

[248] Abreu FOMS, Oliveira EF, Paula HCB, De Paula RCM. Chitosan/cashew gum nanogels for essential oil encapsulation. Carbohydr Polym 2012;89:1277-82. http://dx.doi. org/10.1016/j.carbpol.2012.04.048.

[249] Carneiro HCF, Tonon RV, Grosso CRF, Hubinger MD. Encapsulation efficiency and oxidative stability of flaxseed oil microencapsulated by spray drying using different combinations of wall materials. J Food Eng 2013;115:443-51. http://dx.doi.org/10. 1016/j.jfoodeng.2012.03.033.

[250] Zhang C, Xu W, Jin W, Shah BR, Li Y, Li B. Influence of anionic alginate and cationic chitosan on physicochemical stability and carotenoids bioaccessibility of soy protein isolate-stabilized emulsions. Food Res Int 2015;77:419-25. http://dx.doi.org/ 10.1016/j.foodres.2015.09.020.

[251] Valero-Cases E, Frutos MJ. Effect of different types of encapsulation on the survival of Lactobacillus plantarum during storage with inulin and in vitro digestion. LWT Food Sci Technol 2015;64:824-8. http://dx.doi.org/10.1016/j.lwt.2015.06.049.

[252] Vilela JAP, Perrechil FDA, Picone CSF, Sato ACK, Cunha RL Da. Preparation, characterization and in vitro digestibility of gellan and chitosan-gellan microgels. Carbohydr Polym 2015;117:54-62. http://dx.doi.org/10.1016/j.carbpol.2014.09. 019.

[253] Martinez MJ, Martos G, Molina E, Pilosof AMR. Reduced beta-lactoglobulin IgE binding upon in vitro digestion as a result of the interaction of the protein with casein glycomacropeptide. Food Chem 2016;192:943-9. http://dx.doi.org/10.1016/j. foodchem.2015.07.097.

[254] Lopez-Pena CL, Zheng B, Sela DA, Decker EA, Xiao H, McClements DJ. Impact of $\varepsilon-$ polylysine and pectin on the potential gastrointestinal fate of emulsified lipids: in vitro mouth, stomach and small intestine model. Food Chem 2016;192: 857-64. http://dx.doi.org/10.1016/j.foodchem.2015.07.054.

[255] Majeed H, Antoniou J, Hategekimana J, Sharif HR, Haider J, Liu F, et al. Influence of carrier oil type, particle size on invitro lipid digestion and eugenol release in emulsion and nanoemulsions. Food Hydrocoll 2016;52:415-22. http://dx.doi.org/10. 1016/j.foodhyd.2015.07.009.

[256] Prodigest. SHIME® and M-SHIME®. http://www.prodigest.eu/technology/shimeand-m-shime; 2016. 